\title{
Reperfusion therapy in acute ischemic stroke: dawn of a new era?
}

\author{
Sonu Bhaskar ${ }^{1,2,3,4,6,7^{*}}$ (D) Peter Stanwell ${ }^{7}$, Dennis Cordato ${ }^{2,4,5}$, John Attia ${ }^{7,8}$ and Christopher Levi ${ }^{1,2,3,4,5,6^{*}}$
}

\begin{abstract}
Following the success of recent endovascular trials, endovascular therapy has emerged as an exciting addition to the arsenal of clinical management of patients with acute ischemic stroke (AIS). In this paper, we present an extensive overview of intravenous and endovascular reperfusion strategies, recent advances in AIS neurointervention, limitations of various treatment paradigms, and provide insights on imaging-guided reperfusion therapies. A roadmap for imaging guided reperfusion treatment workflow in AIS is also proposed. Both systemic thrombolysis and endovascular treatment have been incorporated into the standard of care in stroke therapy. Further research on advanced imagingbased approaches to select appropriate patients, may widen the time-window for patient selection and would contribute immensely to early thrombolytic strategies, better recanalization rates, and improved clinical outcomes.
\end{abstract}

Keywords: Stroke, Reperfusion therapy, Prognosis, Endovascular treatment, Neurointervention

\section{Background}

An overwhelming number of studies and clinical trials confirm the efficacy of thrombolytic therapy, in a given therapeutic window, in improving the clinical outcome and recovery of acute ischemic stroke (AIS) patients [1-5]. The primary therapeutic goal for patients with AIS is the timely restoration of blood flow to salvageable ischemic brain tissue that is not already infarcted [6]. Reperfusion therapy using thrombolysis, including intravenous (IV) tissue plasminogen activator (tPA) and endovascular interventions such as mechanical thrombectomy (MT), are the only approved treatments for AIS. Both these treatment options have limitations when used as monotherapies. The only pharmaceutical agent approved for the treatment of AIS is IV-rtPA; however, it is not effective in patients with AIS due to large artery occlusion, where the clot burden is very high. In such patients, MT has proven more effective. Currently, the primary criterion for candidate selection in reperfusion is the time from stroke symptom onset. Reperfusion therapy must be administered within a narrow window time of up to $4.5 \mathrm{~h}$ after symptom onset for IV-tPA,

\footnotetext{
* Correspondence: Sonu.Bhaskar@health.nsw.gov.au;

Christopher.Levi@unsw.edu.au

${ }^{1}$ Western Sydney University (WSU), School of Medicine, South West Sydney

Clinical School, Sydney, NSW 2170, Australia

Full list of author information is available at the end of the article
}

and up to 6-8 h for endovascular MT. The restriction on IV-tPA treatment beyond $4.5 \mathrm{~h}$ disqualifies the majority of stroke patients admitted beyond this time-window (around $85 \%)$, thereby drastically limiting the eligible population [710].

In this article, we review the literature on the various reperfusion strategies available for AIS patients, and provide insights on potential applications, limitations of various reperfusion strategies and role of imaging in guiding therapy.

\section{Evolution of reperfusion therapy}

Thrombolysis, commonly known as "clot-busting", is a pharmacological treatment using an infusion of analogues of tPA which leads to the breakdown (lysis) of the culprit blood-clot. Thrombolytic drugs dissolve blood clots by activating a proteolytic enzyme, plasminogen, to plasmin. Fibrin molecules provide the structural scaffold for blood clots, and plasmin cleaves cross-linkages between fibrin molecules. Subsequently, the clot becomes soluble and undergoes further degradation through proteolysis by other enzymes, eventually restoring blood flow. Due to their mechanism of action, thrombolytic 
drugs are also referred to as "plasminogen activators" or "fibrinolytic drugs". The three major classes of plasminogen activators are (i) tPA, (ii) streptokinase (SK), and (iii) urokinase (UK). Thrombolytic drugs differ in the mechanism by which they act on fibrin clots. The sequence that leads to the breakdown of the clot or fibrinolysis by tPA is shown in Fig. 1. At first, tPA binds to clot-bound fibrin. This activates fibrin-bound plasminogen from an inactive form to plasmin, the active form. The enzyme plasmin acts on the fibrin mesh, leading to the breakdown of the fibrin scaffold. Subsequently, the dissolution of the fibrin clot produces circulating fibrin fragments called fibrin degradation products. These products prevent the conversion of fibrinogen to fibrin, which slows down clot formation. The liver and kidney, ultimately clear these products, as well as other proteases. Two serine protease inhibitors, namely plasminogen activator inhibitor-1 and 2 (PAI-1 and PAI-2), endogenously inhibit tPA and UK. Alpha 2-antiplasmin and alpha 2macroglobulin also act as inhibitors of plasmin. Factors XII, XIIa, and Kallikrein stimulate the process of plasmin formation from plasminogen. On the other hand, another factor called thrombin-activatable fibrinolysis inhibitor (TAFI) alters the fibrin to make it more resistant to plasminogen activated by tPA. Efficacy of thrombolytic drugs depends on the size, location, and age of the clot because of the increased density of fibrin crosslinking which make clots more compact and harder to dissolve the older they are.
Some of the known tPA analogues are Alteplase (Activase $^{\oplus}$; recombinant tPA (rtPA)), Retaplase (Retavase ${ }^{\circ}$ ) and Tenecteplase (TNK-tPA). Alteplase, the most commonly used thrombolytic drug, is a fibrin-selective analogue of tPA administered intravenously or intraarterially. It is the only Food and Drug Administration (FDA)-approved thrombolytic agent for the treatment of AIS. rtPA causes lysis of fibrin; thereby dissolving the thrombus and resulting in recanalization of the occluded artery [6]. It has a short half-life $(\sim 5 \mathrm{~min})$ and is therefore administered as an IV bolus followed by an infusion. Several trials including the National Institute of Neurological Disorders and Stroke (NINDS) [11] and European Collaborative Acute Stroke Study (ECASS) have demonstrated evidence for the benefit of rtPA for a select group of AIS patients. In comparison to rtPA, TNK-tPA has a greater binding affinity for fibrin, higher resistance to inactivation by PAI-1, and a longer half-life.

Urokinase, also known as urinary-type plasminogen activator (uPA), is found in urine. Clinically, UK is used as a thrombolytic drug in conditions such as pulmonary embolism, myocardial infarction, and severe deep venous thrombosis (DVT). In comparison to rtPA, SK and UK lack fibrin specificity and bind equally to circulating plasminogen and clot-bound plasminogen. On binding with plasminogen, SK forms a complex that activates plasmin, triggering a proteolytic cascade. The proteolytic cascade leads to thrombolysis (clot degradation in AIS) or extracellular matrix degradation (e.g., tissue

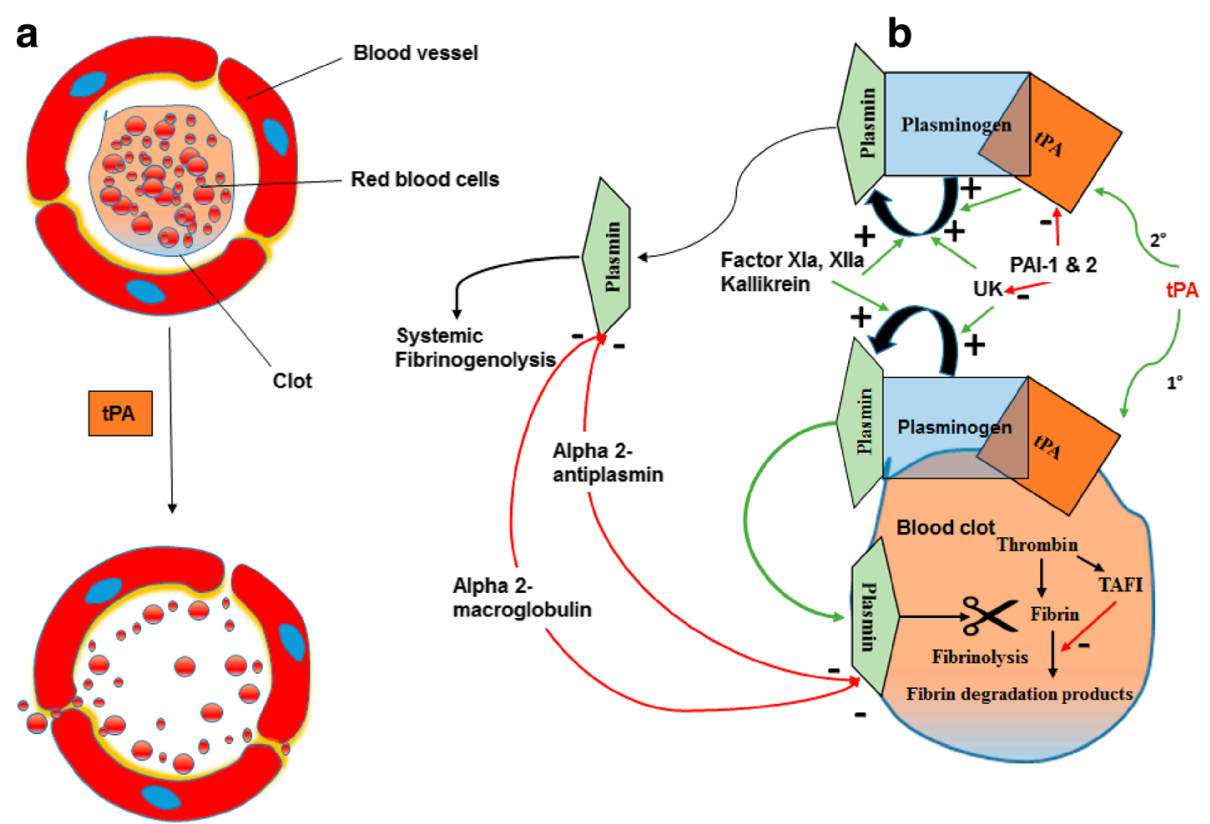

Fig. 1 The illustration of the fibrinolytic mechanisms: (a) tissue plasminogen activator (tPA) causes breakdown of the clot, and (b) detailed mechanism of fibrinolysis. Green arrow denotes activation/stimulation, and the red arrow indicates inhibition. tPA = tissue plasminogen activator; UK $=$ Urokinase; $\mathrm{PAI}=$ plasminogen activator inhibitor 
degradation causing tissue invasion and metastasis in tumour malignancy) depending upon the physiological environment. Therefore, SK and UK have less favourable adverse event profiles than rtPA. Thrombolytic drugs can be used as (a) Intravenous, and (b) Intra-arterial. Next, we will discuss the important aspects of these thrombolytic procedures.

\section{Intravenous thrombolysis}

Table 1 gives a detailed overview of clinical trials that evaluated the "time is brain" paradigm. The selection of patients for IV thrombolysis was based mainly on time since stroke onset. All of these trials used non-contrast CT (NCCT) for assessment of parenchymal injury. The exclusion criteria were the presence of a large infarct occupying more than one-third of the MCA territory or causing severe oedema or mass effect visible on NCCT [7].

The field of acute ischemic treatment using thrombolytic therapy before 1995 was despairing given the high rates of intracerebral haemorrhage in early clinical trials, which changed dramatically after the publication of results of NINDS stroke trial, showing benefit for IV Alteplase within $3 \mathrm{~h}$ of symptom onset [4]. The trial recruited 624 patients who were randomly assigned to treatment with IV Alteplase $(0.9 \mathrm{mg} / \mathrm{kg}$ up to $90 \mathrm{mg} ; 10 \%$ as a bolus followed by a 60 -min infusion [12]) or placebo. A significantly greater proportion of patients (38 (Alteplase) vs. $21 \%$ (placebo)) who received Alteplase showed a favourable clinical recovery at 90 days after stroke. However, the Alteplase group showed a dramatic 10-fold increase in symptomatic intracerebral haemorrhage. There was no significant difference in 90-day mortality between the two groups. Notably, less than $1 \%$ of patients experienced severe systemic bleeding at 3 months. A one-year follow-up study showed patients with AIS treated with Alteplase within $3 \mathrm{~h}$ after the onset of stroke were more likely to have minimal or no disability in comparison to patients receiving placebo $[5,13]$.

Subsequent serial observational registries and prospective randomised controlled studies conducted to investigate the safety and efficacy of IV Alteplase within the eligible time window showed a time-dependent relationship, with earlier treatment associated with larger proportional therapeutic benefits [3, 14, 15]. The ECASS-III trial showed clear benefit for patients treated between 3 and $4.5 \mathrm{~h}$ after stroke onset [16], which the previous RCTs failed to show because the earlier trials recruited small numbers of patients in this time window, and had treatment time windows of up to $6 \mathrm{~h} \mathrm{[17-19].} \mathrm{Other} \mathrm{studies} \mathrm{including} \mathrm{the} \mathrm{Canadian} \mathrm{Alte-}$ plase for Stroke Effectiveness Study (CASES) registry [20], and Safe Implementation of Thrombolysis in Stroke-International Stroke Thrombolysis Register (SITS-ISTR) [21] provided further evidence of benefit for the administration of IV-rtPA therapy in the 3$4.5 \mathrm{~h}$ treatment window. These registries, CASES and SITS-ISTR, found comparable rates of mortality, functional independence, and incidence of symptomatic $\mathrm{ICH}$ within $24 \mathrm{~h}$ [22]. The extension of the timewindow up to $4.5 \mathrm{~h}$ obviously offers an opportunity for treatment for more patients [21]. With regard to the treatment beyond 4.5 and up to $6 \mathrm{~h}$, three trials including the Alteplase Thrombolysis for Acute Noninterventional Therapy in Ischemic Stroke (ATLANTIS-A for

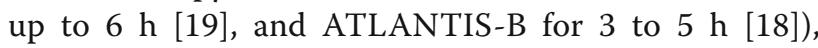
ECASS-II (for 0-6 h) [17], and the third International Stroke Thrombolysis Trial (IST-3) (for 0-6 h) [15] failed to demonstrate a treatment benefit for rtPA. However, a recent meta-analysis of 12 trials including 7012 patients, who received Alteplase within $6 \mathrm{~h}$ of onset of AIS, found significant improvement in the favourable outcome (mRS $0-1$ ), functional independence (mRS 0-2), and survival rates at the end of final follow-up [23]. On the one hand, this analysis reinforces the need to treat patients as early as possible, though, it also suggested that some patients might benefit from Alteplase up to $6 \mathrm{~h}$ after stroke [15]. However, subgroup analysis for the treatment window between 4.5 and $6 \mathrm{~h}$ was not presented. Moreover, no significant trend toward a favourable outcome was found in a subset of patients $(n=4971)$ who received Alteplase between 3 and $6 \mathrm{~h}$. The overall trend towards a beneficial outcome in $0-6$-h window may have been influenced by the dominant trend observed in $0-3-\mathrm{h}$ window. Pooled analysis of three trials, published in 2004, including the NINDS trials (3-h window), ECASS trials (6-h window), and two ATLANTIS trials (6-h and 5 -h window), demonstrated strong association between rapid treatment and favourable outcome for patients receiving IV thrombolytic therapy within a $3 \mathrm{~h}$ time window [2]. Moreover, the results of two other recent pooled analyses published in $2010 \quad(n=2775$ pooled from ECASS, ATLANTIS, NINDS, and Echoplanar Imaging Thrombolysis Evaluation Trial (EPITHET) trials and $2014(n=6756$ pooled from IST-3, ECASS, EPITHET, ATLANTIS, NINDS) also indicated modest, yet clinically relevant, benefits to a select group in the therapeutic window of three to $4.5 \mathrm{~h}[2,3,14,24]$. However, risk outweighed benefit beyond $4.5 \mathrm{~h}[3,14$, 15]. In light of the emerging evidence and to provide more patients with an opportunity to receive tPA, acute stroke guidelines for the administration of rtPA following AIS have been revised by both the European Stroke Organization (ESO) [25] and American Heart Association/American Stroke Association (AHA/ASA) [26] by expanding the window of treatment from $3 \mathrm{~h}$ to $4.5 \mathrm{~h}$. Interestingly, the Federal Drugs Agency (FDA) has not yet approved this extended indication. 
Table 1 List of thrombolytic trials in acute ischemic stroke based on time-window

\begin{tabular}{|c|c|}
\hline Trial (n) & Remarks \\
\hline & TIME WINDOW 0-3 HOURS \\
\hline $\operatorname{NINDS}[4,231](n=624)$ & $\begin{array}{l}\text { Time window: } 0-3 \mathrm{~h}, 3-6 \mathrm{~h} \\
\text { Endpoints: A favourable outcome was defined as recovery with minimal or no deficit } 3 \text { months after treatment using } \\
\text { four outcome measures: the } \mathrm{BI} \geq 95, \mathrm{mRS} \text { seven } \leq 1 \text {, Glasgow Outcome Scale } 8 \text { of } 1 \text {, and NIHSS score } \leq 1 \text {. } \\
\text { Results: Treatment with } \mathrm{tPA} \text { within } 3 \mathrm{~h} \text { of the onset led to the improved clinical outcome at } 3 \text { months, and increase in } \\
\text { the incidence of symptomatic ICH. }\end{array}$ \\
\hline SITS-MOST [232] $(n=6483)$ & $\begin{array}{l}\text { Time window: } 0-3 \mathrm{~h} \\
\text { Endpoints: Primary outcomes were symptomatic (a deterioration in NIHSS score of } \geq 4 \text { ) ICH type } 2 \text { within } 24 \mathrm{~h} \text { and } \\
\text { mortality at } 3 \text { months. Functional independence (defined by an mRS score of } 0-2 \text { at } 90 \text { days) was a secondary outcome. } \\
\text { Results: Treatment with Alteplase is safe and effective when used within } 3 \mathrm{~h} \text { of stroke onset. }\end{array}$ \\
\hline TESPI $[64,233](n=248)$ & $\begin{array}{l}\text { Time window: } 0-3 \mathrm{~h} \\
\text { Endpoints: Primary endpoint for efficacy was the disability at day } 90 \text {, dichotomized as a favourable outcome (mRS 0-2) or } \\
\text { unfavourable outcome (mRS 3-6) [64]. The end-point for safety is symptomatic ICH radiologically confirmed on the 22-36 h } \\
\text { post-treatment scan combined with neurological deterioration leading to an increase of } \geq 1 \text { point/s on the NIHSS scale. } \\
\text { Results: Higher mortality in patients aged }>80 \text { years than younger patients treated with IV-rtPA. No significant differences } \\
\text { in symptomatic ICH nor for a favourable outcome. Thrombolytic therapy should not be a priori denied for appropriately } \\
\text { selected }>80 \text {-year old patients [233]. }\end{array}$ \\
\hline
\end{tabular}

Time window: $0-3 \mathrm{~h}$

Endpoints: Primary endpoints were symptomatic (deterioration in NIHSS score $\geq 4$ or death within the first $24 \mathrm{~h}$ ) intracerebral haemorrhage type $22-36 \mathrm{~h}$ after the thrombolysis, and mortality at 90 days follow-up. The secondary outcome was functional independence (mRS 0-2) at three-months [234].

Results: IV alteplase is safe and efficient in the treatment of ischaemic stroke in Asian population in congruence to the observations of SITS trials performed on European population.

TIME WINDOW 3-4.5 HOURS

ECASS-III [11] $(n=821)$

Time window: $3-4.5 \mathrm{~h}$

Endpoints: Primary outcome was a disability at 3 months, assessed by the mRS as either favourable (score of 0 or 1) or unfavourable (score of 2 to 6). Secondary end-points included combined BI and RS, Scandinavian Stroke Scale (SSS) at 90 days, and 30 day mortality. Tertiary outcomes included early neurologic recovery (SSS) and duration of in-hospital stay. Results: Significant benefit of IV-rtPA when administered up to $4.5 \mathrm{~h}$. Symptomatic ICH is significantly more likely with alteplase than with placebo. No difference in mortality between the groups.

CASES [20] $(n=1112)$

Time window: $3-4.5 \mathrm{~h}, 0-3 \mathrm{~h}$

Endpoints: The primary endpoints were mRS at 90 days, mortality and symptomatic ICH. An mRS 0-1 at 90 days was defined as a favourable outcome.

Results: IV alteplase is efficacious in treating AIS patients in $3-4.5 \mathrm{~h}$ window; however, there is a tendency towards increased risk of symptomatic $\mathrm{ICH}$ in the later time window.

Time window: $3-4.5 \mathrm{~h}$

Endpoints: Primary endpoints were functional independence at 3 months, and incidence of symptomatic ICH. Results: Safety and the functional outcome less favourable after $3 \mathrm{~h}$.

\section{TIME WINDOW 4.5-6 HOURS}

Time window: $3-5 \mathrm{~h}$

Endpoints: Primary efficacy endpoint was an excellent neurologic recovery at day 90 (NIHSS $\leq 1$ ); Secondary endpoints included remarkable recovery on functional outcome measures (BI, mRS, and Glasgow Outcome Scale) at days 30 and 90 . Serious adverse events such as symptomatic $\mathrm{ICH}$ were also assessed.

Results: No significant rtPA benefit on the 90 day efficacy endpoints in patients treated between 3 and $5 \mathrm{~h}$. A significant increase in the risk of symptomatic ICH with treatment using IV-rtPA.

ECASS-II [17] $(n=800)$

Time window: $0-3 \mathrm{~h}$ and $3-6 \mathrm{~h}$

Endpoints: The primary outcome was the mRS at 90 days, dichotomised for favourable (score 0-1) and unfavourable (score 2-6) outcome.

Results: Trend towards benefit for alteplase, though not statistically significant. Increased risk of symptomatic ICH (8.6\% alteplase-group vs. 3.4\% placebo-group).

Time window: 0-6 h

Endpoints: Primary efficacy endpoints were the number of patients with a decrease of $\geq$ points on the NIHSS scale at $24 \mathrm{~h}$ and day 30, along with infarct volume at day 30 . Secondary outcomes included mortality and functional status on the $\mathrm{Bl}$ and $\mathrm{mRS}$ scales at days 30 and 90 .

Results: Significantly higher proportion of 4-point NIHSS improvement at $24 \mathrm{~h}$ for rtPA groups (40\%) vs. placebo (21\%). The trend reversed at 30 days with more improvement observed in placebo (75\%) vs. rtPA patients (60\%). rtPA is strongly correlated with an increased risk of $\mathrm{ICH}$, especially in patients treated between 5 and $6 \mathrm{~h}$ after onset.

IST-3 [15] $(n=3035)$

Time window: 0-6 h

Endpoints: Primary outcome was the proportion of patients who were alive and independent (defined by an Oxford Handicap Score (OHS) of 0-2) at 6 months. Symptomatic ICH recorded at 7 days, and at 6 months.

Results: Higher proportion of symptomatic ICH at 7 days in the rtPA group (7\%) vs. control group (1\%), and deaths at

7 days in rtPA (11\%) vs. control group (7\%). A similar number of fatalities in either rtPA or control groups (27\% each).

Despite early hazards, IV alteplase improved functional outcome.

IV Intravenous; rtPA Recombinant tissue plasminogen activator; NINDS National Institute of Neurological Disorders and Stroke; mRS Modified Rankin Score; $B$ I Barthel Index; SITS-MOST Safe Implementation of Thrombolysis in Stroke-Monitoring Study; NIHSS National Institute of Health Stroke Scale; ICH Intracerebral haemorrhage; TESPI Thrombolysis in Elderly Stroke Patients in Italy; SITS-NEW Safe Implementation of Thrombolysis in Stroke-Non-European Union World; ECASS European Cooperative Acute Stroke Study; ATLANTIS The Alteplase Thrombolysis for Acute Noninterventional Therapy in Ischemic Stroke; CASES Canadian Alteplase for Stroke Effectiveness Study; IST-3 third international stroke trial 
Some contraindications limit the use of IV-rtPA in AIS (see Table 2) [27]. Moreover, the narrow time window of $4.5 \mathrm{~h}$ along with the multitude of contraindications prevent many patients from receiving treatment; indeed, less than $3 \%$ of patients presenting with AIS receive IVrtPA [28]. Other limitations of IV-rtPA are: (a) increased rate of mortality and intracranial bleeding in internal carotid artery occlusion (ICA) [29-32] or other disabling strokes such as those with no detectable residual flow signals [33-35], (b) low recanalization rate ranging from 13 to $50 \%$ in large artery occlusion such as the proximal middle cerebral artery (MCA), the ICA, or the basilar artery [27, 35-41], and (c) unresponsiveness to large thrombi (especially when the thrombus length exceeds $8 \mathrm{~mm}$ [42-45], or location is proximal, such as terminal carotid artery occlusion [34, 46]. One study found only 10 and $25 \%$ of ICA and proximal MCA occlusions are recanalizable by IV-rtPA [47]. Incomplete recanalization is often observed in patients treated with IV-rtPA. For instance, $70 \%$ of patients who received IV-rtPA were found to have angiographically confirmed residual

Table 2 Contraindications for intravenous recombinant tissue plasminogen activator (rtPA) in acute ischemic stroke

Contraindications applicable to use of intravenous rtPA in acute ischemic stroke (AIS)

Onset of stroke symptoms more than $4.5 \mathrm{~h}^{\psi}{ }^{\psi}$

History of stroke or significant head trauma in previous 3 months

Previous intracranial haemorrhage.

Symptoms are suggestive of subarachnoid haemorrhage.

Prolonged blood pressure elevation (systolic $\geq 185 \mathrm{mmHg}$ or diastolic $\geq 110 \mathrm{mmHg}$ ).

Hypoglycemia (serum glucose $<50 \mathrm{mg} / \mathrm{dL}(<2.8 \mathrm{mmol} / \mathrm{L})$ ).

Active internal bleeding, acute bleeding diathesis, including platelet count $<100,000 / \mathrm{mm}^{3}$, current anticoagulant use with an INR $>1.7$, or PT $>15 \mathrm{~s}$.

Heparin use within $48 \mathrm{~h}$ with an abnormally elevated aPTT.

Arterial puncture at noncompressible site in previous 7 days.

History of gastrointestinal tract haemorrhage within 21 days.

The recent history of major surgery intracranial or intraspinal surgery within 14 days.

Previous history of a previous aneurysm, arteriovenous malformation, or intracranial neoplasm.

Current use of a direct thrombin inhibitor or direct factor Xa inhibitors with an evidence of anticoagulation effect by laboratory tests such as aPTT, INR $<E C T, \Pi$, or relevant factor Xa activity assays.

Early ischemic changes are visible on CT in more than one-third of MCA artery vascular territory consistent with irreversible injury or evidence of haemorrhage on CT scan.

${ }^{\Psi}$ Additional criteria applicable for IV-rtPA between 3 to $4.5 \mathrm{~h}$ : patient older than 80 years, severe stroke (baseline NIHSS >25), no prior history of diabetes mellitus and AIS (both), and not currently on any oral anticoagulants regardless of INR.

CT Computed tomography; INR International normalised ratio; IV-rtPA Intravenous recombinant tissue plasminogen activator; MCA Middle cerebral artery; NIHSS National Institute of Health Stroke Scale; PT Prothrombin time; aPTT Activated partial thromboplastin time; ECT Ecarin clotting time thrombus requiring complimentary intra-arterial treatment such as clot angioplasty [48].

Novel therapies are being currently investigated to overcome the limitations of IV thrombolysis or to extend the time window of treatment, for example: (i) use of alternative fibrinolytic agents such as desmoteplase [49-53], argatroban [54], tenecteplase [19, 55], albumin [56], and plasmin [57], (ii) mixed approaches that involve combination of rtPA and other agents or therapies such as GP IIb/IIIa antagonists [58-60], antiplatelet agents (e.g., acetylsalicylic acid [61-63]), low-molecularweight heparin $[64,65]$, and sonothrombolysis [66-69] to enhance microcirculatory flow, reduce residual thrombus, and boost lytic efficacy, (iii) use of noninvasive or minimally invasive methods such ventilator support [70], and pterygopalatine ganglion and petrosal nerve stimulation [71] to augment cerebral blood flow by cerebral vasodilation and alleviate blood flow steal, and (iv) endovascular procedures such as intra-arterial thrombolysis, stenting, and angioplasty to achieve greater clot manipulation and significantly higher rates of arterial recanalization $[46,72]$.

\section{Endovascular treatment Intra-arterial thrombolysis}

Intra-arterial (IA) thrombolysis has emerged as a promising intervention, especially for AIS patients with contraindications for IV-tPA [73-75]. Intra-arterial procedures are performed under direct visualisation; therefore, one can limit the dose of the fibrinolytic agent, mechanically manipulate the clot if required and deliver higher concentrations of the agent to the clot target (local delivery) with reduced systemic effects [76, 77]. IA can also deliver higher recanalization rates. However, IA therapy also has its unique set of challenges and disadvantages. Mechanical manipulation of a clot during IA may also increase the risk of injuring adjacent blood vessels. Moreover, advanced training is required for neuro interventionists or neuroradiologists to gain expertise in IA procedures which can be demanding [74, 78-80]. As such, endovascular treatment is only available in a limited number of specialised stroke centres.

Prolyse in Acute Cerebral Thromboembolism (PROACT) was the first randomized trial (phase II study; $n=46$ ) of $6 \mathrm{mg}$ recombinant pro-urokinase (rpro$\mathrm{UK})$ versus placebo undertaken in patients with angiographically documented proximal MCA occlusion to test the safety, recanalization frequency, and clinical efficacy of intra-arterial local infusion of plasminogen activators in AIS patients with symptomatic MCA occlusion of less than 6 h' duration [81]. Investigators found a significant association of intra-arterial local rpro-UK infusion with greater frequency of recanalization in acute stroke patients with M1 or M2 occlusions compared with 
placebo $(57.7 \%$ vs. $14.3 \%, P=0.017)$. However, an increased, though not significant, symptomatic haemorrhage rate was also reported. Subsequently, a phase III, PROACT II study was undertaken, involving fifty-four stroke centers in the United States and Canada, with an increased $9 \mathrm{mg}$ dosage of r-pro-UK administered over $2 \mathrm{~h}$ infusion while using heparin in low dose (from PROACT I) to improve the recanalization in addition to containing symptomatic brain haemorrhages [82]. Out of 180 randomied patients with AIS, treatment with IA r-pro UK within $6 \mathrm{~h}$ of the onset of AIS caused by MCA occlusion was significantly associated with improved clinical outcome at 90 days. The IA r-pro-UK group demonstrated significantly higher recanalization rates (66\% vs. $18 \%, P<0.001$ ), and increased favourable independent outcome $(60 \%$ vs. $18 \%, P<0.001)$ than the IA heparin alone. However, higher frequency of early symptomatic intra-cerebral haemorrhage (ICH) was also observed in the intervention group (10\% vs. $2 \%)$. Overall, the proportion of ICH was relatively higher in PROACT II than previous IV thrombolysis trials [81], perhaps due to greater baseline National Institutes of Health Stroke Scale (NIHSS) in PROACT II in comparison to other trials. The median baseline stroke severity in PROACT was 17 , in contrast to 14 and 11 in the NINDS and ECASS II trials respectively. Contrary to the positive findings of PROACT II, another large open-label trial, Local Versus Systemic Thrombolysis for Acute Ischemic Stroke (SYNTHESIS) Expansion, found that IA thrombolytic therapy was not superior to standard treatment with IV-rtPA [83]. Disability-free outcome at 90 days was not significantly different between the IA thrombolytic and IV-rtPA groups $(30.4 \%$ vs. $34.8 \%$; adjusted odds ratio $=0.71,95 \%$ CI $0.44-1.14)$. Another randomized trial, the Middle Cerebral Artery Embolism Local Fibrinolytic Intervention Trial (MELT), conducted in Japan, to investigate the safety and clinical efficacy of intra-arterial urokinase (UK) in patients within $6 \mathrm{~h}$ of onset of stroke with angiographically documented M1 or M2 occlusion, found a trend towards favourable outcome (defined by Modified Rankin Score (mRS) 0-2) at 90 days, and a substantial increase in likelihood of excellent outcome (defined by mRS $0-1$ ) [84]. However, the primary endpoint (good outcome; mRS $0-2$ ) did not reach statistical significance as the trial was aborted prematurely. A meta-analysis of five RCTs with 395 AIS patients with MCA occlusion compared IA thrombolysis with control (IV heparin) [85]. The study concluded that IA thrombolysis was significantly associated with substantial increases in recanalization rates and good (odds ratio $=2.05 ; 95 \% \mathrm{CI}, 1.33$ to $3.14 ; P=0.001$ ) and excellent outcomes (odds ratio $=2.14 ; 95 \%$ CI, 1.31 to 3.51; $P=0.003)$ in AIS. Intra-arterial thrombolytic treatment is gaining traction at some comprehensive stroke facilities at tertiary hospitals. It is often administered as an off-label therapy within $6 \mathrm{~h}$ of onset of stroke in patients with anterior circulation and up to $12-24 \mathrm{~h}$ after onset in the posterior circulation [74]. As per the guidelines of the AHA issued in 2005, and again in 2013, IA thrombolysis has been recommended in appropriately selected AIS patients with MCA occlusions within $6 \mathrm{~h}$ provided they were not candidates for IVrtPA (Class I, Level of Evidence: B) [86]. The FDA has not approved IA-pro-UK.

\section{Mechanical Thrombectomy (MT)}

MT involves a minimally invasive surgical procedure using a microcatheter and other thrombectomy devices to trap and remove the blood clot from an occluded artery. MT, delivered as a stand-alone treatment or in conjunction with systemic thrombolysis (IV-rtPA or IA thrombolysis), is currently the standard of care for AIS therapy [87]. MT devices can be classified into different subtypes based on their mechanism of action: (a) coil retriever, (b) aspiration, (c) stent-retriever, and (d) mechanical clot disruption, using laser or ultrasound. A comprehensive list of past and current MT devices is given in Table 3. Coil retriever devices and the early Penumbra aspiration system $[88,89]$ were the first generation of MT devices; they failed to show long-term improvements in clinical outcomes despite satisfactory revascularization efficacy (up to 50\%) [90]. Coil retrievers such as MERCI [91-94], Phenox [95, 96] and Catch retrievers [97-99] use microcatheter to deliver a coiled wire across the targeted clot in the occluded artery [91-94]. Once the coil is deployed, the neuro interventionist pulls both the coil and the clot towards the catheter leading to the removal of the clot [100]. Aspiration devices such as Penumbra (Penumbra Inc., US) use vacuum aspiration to remove target clot in the occluded artery. The early generation of aspiration devices was often subject to clogging of the aspiration tips; this has been overcome in the later models by the addition of a separator wire with a bulbous tip inside the bore, which can be pushed in and pulled out by the neurointerventionist. The continual back and forth motion cleave the clot detaching it from the lumen. Eventually, the clot is sucked in, without clogging the tip, ahead of the catheter [101]. The second generation of MT devices used self-expanding stents to trap the clot by deploying them in the occluded artery [101]. They were originally conceived for stentassisted coiling and retraction of aberrant coils dislodged during the endovascular procedures. These selfexpanding stents are first lodged across the thrombus within the vessel wall, following which, once the clot is entrapped, the stent-clot combination is subsequently retracted back under constant aspiration into the delivery guide microcatheter. Some clinical trials using 
Table 3 List of mechanical thrombectomy (MT) devices

\begin{tabular}{|c|c|c|c|}
\hline MT device & Vendor & Mechanism of action & References \\
\hline Merci Clot Retriever & Concentric Medical & Coil retriever & [91-94] \\
\hline Phenox & Phenox, Bochum, Germany & Coil retriever/Aspiration & {$[95,96]$} \\
\hline Catch & Balt, Montmorency, France & Coil retriever & [97-99] \\
\hline Distal Access Catheter (DAC) & DAC; Concentric Medical, US & Coil retriever & [129] \\
\hline Early Penumbra & Penumbra Inc., US & Aspiration & {$[88,89,235-237]$} \\
\hline AngioJet & Possis Medical, MN, USA & Aspiration/Rheolytic thrombectomy ${ }^{a}$ & [238-241] \\
\hline EKOS Primo & EKOS, Bothell, WA & Ultrasound-based on mechanical clot disruption & [242] \\
\hline Neuroform & Stryker Neurovascular, US & Stent Retriever & {$[243,244]$} \\
\hline Enterprise & Codman, Raynham, MA, US & Stent Retriever & {$[245-247]$} \\
\hline Solitaire & Covidien/Medtronic, Dublin, Ireland & Stent retriever & {$[126,223,248-254]$} \\
\hline Trevo & Stryker, Kalamazoo, Michigan, US & Stent Retriever & {$[92,255-259]$} \\
\hline ReVive ${ }^{T M}$ & Micrus Endovascular, CA, US & Stent Retriever & {$[260,261]$} \\
\hline APERIO & Acandis, Pfzorheim, Germany & Stent Retriever & {$[261-263]$} \\
\hline $\begin{array}{l}\text { Embotrap Revascularization } \\
\text { system }\end{array}$ & Neuravi, Ireland & Stent Retriever & [264] \\
\hline pREset & Phenox, Bochum, Germany & Stent Retriever & [265] \\
\hline The Mindframe Capture LP & Medtronic, Minneapolis, Minnesota, USA & Stent Retriever & {$[266,267]$} \\
\hline ERIC & MicroVention, CA, US & Stent Retriever & [268] \\
\hline SOFIA & MicroVention, CA, US & Stent Retriever & [269-271] \\
\hline Penumbra 5MAX ACE & Penumbra Inc., California, US & Aspiration & {$[103,104,106,107,272]$} \\
\hline Penumbra ACE 64 & Penumbra Inc., California, US & Aspiration & {$[105,107,273,274]$} \\
\hline Penumbra 3D separator & Penumbra Inc., California, US & Aspiration & {$[108,109]$} \\
\hline LaTIS Neurolaser laser & Latis Inc., Minneapolis, Minn & Laser recanalization based mechanical clot disruption & [275] \\
\hline EPAR laser & EndoVasix, Belmont, CA & Laser recanalization based mechanical clot disruption & [130] \\
\hline MicroLysUS catheter & EKOS, Bothell, WA, US & Ultrasound-based mechanical clot disruption & [276] \\
\hline Wingspan & Stryker Neurovascular, Fremont, CA, US & Ultrasound-based mechanical clot disruption & {$[277-284]$} \\
\hline
\end{tabular}

ERIC Embolus Retriever with Interlinked Cage; SOFIA Soft Torqueable Catheter Optimized For Intracranial Access

${ }^{a}$ Rheolytic thrombectomy refers to the mechanical procedure of removing thrombus using multiple high-velocity, high-pressure saline jets of saline from the tip of a catheter using an AngioJet system [285]

the new generation stent retrievers, such as Solitaire, Trevo Pro, and ReVive, have yielded recanalization rates as high as $85 \%$ in AIS with large vessel occlusion [93, 100-102].

Combined interventions, using both suction embolectomy with large bore catheters and mechanical retrieval using stent retrievers, have shown promise in recent studies [103]. In this technique, aspiration of the clot, a cheaper alternative, is attempted first using a large bore microcatheter such as the Penumbra MAX systems [104-107]. If the aspiration fails, mechanical retrieval is attempted by inserting the stent retrievers via the aspiration catheter. Using this sequential combination, phenomenal recanalization rates of up to $95 \%$ have been achieved [103], compared with stand-alone direct aspiration rates of $78 \%$. Another application of combined approach is the latest generation Penumbra device called Penumbra 3D separator, which incorporates lesional aspiration technology coupled with an advanced stent retriever device, allowing the breakdown of a clot in addition to radial direction using stent struts [100, 108]. Penumbra 3D separators have demonstrated good revascularization of large vessel occlusions and a greater rate of functional independence at 90 days $[108,109]$.

A detailed comparative overview of successful clinical trials concerning endovascular treatment for AIS along with the imaging and clinical selection criteria, and the outcome measures are presented in Table 4.

Following the success of five multicentre, open-label, randomized controlled endovascular acute stroke trials including MR CLEAN (Multicenter Randomized Clinical Trial of Endovascular Treatment for Acute Ischemic Stroke in the Netherlands) [110], ESCAPE (Endovascular Treatment for Small Core and Anterior Circulation Proximal Occlusion with Emphasis on Minimizing CT to Recanalization Times) [111], SWIFT PRIME (Solitaire 
Table 4 Comparison of baseline characteristics and outcome measures of the recent endovascular trials $[27,194,286]$

\begin{tabular}{|c|c|c|c|c|c|c|c|}
\hline Trials & MR CLEAN [110] & ESCAPE [111] & EXTEND-IA [76] & $\begin{array}{l}\text { SWIFT PRIME } \\
{[112]}\end{array}$ & REVASCAT [113] & $\begin{array}{l}\text { THERAPY } \\
\text { [128] }\end{array}$ & $\begin{array}{l}\text { THRACE } \\
{[127]}\end{array}$ \\
\hline Region & Netherlands & $\begin{array}{l}\text { United States, } \\
\text { Canada, South Korea, } \\
\text { Ireland, United Kingdom }\end{array}$ & $\begin{array}{l}\text { Australia and } \\
\text { New Zealand }\end{array}$ & $\begin{array}{l}\text { United States } \\
\text { and Europe }\end{array}$ & Spain & $\begin{array}{l}\text { United } \\
\text { States }\end{array}$ & France \\
\hline Number of centres & 16 & 22 & 10 & 39 & 4 & 4 & 26 \\
\hline $\begin{array}{l}\text { Number of patients; } \\
\mathrm{n}(\mathrm{CG} / \mathrm{IA})\end{array}$ & $500(267 / 233)$ & $315(150 / 165)$ & $70(35 / 35)$ & $196(98 / 98)$ & $206(103 / 103)$ & $108(54 / 54)$ & $\begin{array}{l}412 \\
(208 / 204)\end{array}$ \\
\hline \multicolumn{8}{|c|}{ BASELINE CHARACTERISTICS } \\
\hline Age Range & $\geq 18$ & $\geq 18$ & $\geq 18$ & $18-80$ years & $18-80$ years & $18-85$ & $18-80$ \\
\hline NIHSS Range & $\geq 2$ & $>5$ & N.R. & $8-29$ & $\geq 6$ & $\geq 8$ & $10-25$ \\
\hline Control group & $\begin{array}{l}\text { Standard medical } \\
\text { therapy } \\
(+/- \text { IV tPA) }\end{array}$ & $\begin{array}{l}\text { Standard medical } \\
\text { therapy }(+/- \text { IV tPA) }\end{array}$ & IV-tPA only & IV-tPA only & $\begin{array}{l}\text { Standard medical } \\
\text { therapy } \\
(+/- \text { IV tPA })\end{array}$ & IV-tPA only & IV-tPA only \\
\hline Intervention group & IAT & IAT & $\begin{array}{l}\text { ET with Solitaire } \\
\text { FR stentriever }\end{array}$ & $\begin{array}{l}\text { ET with Solitaire } \\
\text { FR stentriever }\end{array}$ & $\begin{array}{l}\text { ET with } \\
\text { Solitaire FR } \\
\text { stentriever }\end{array}$ & $\begin{array}{l}\text { ET with } \\
\text { Penumbra } \\
\text { aspiration } \\
\text { system }\end{array}$ & $\begin{array}{l}\text { Endovascular } \\
\text { MT }\end{array}$ \\
\hline $\begin{array}{l}\text { Intervention using } \\
\text { Stent retriever in } \\
\text { IA arm }\end{array}$ & $81.5 \%$ & $86.1 \%$ & $100 \%$ & $100 \%$ & $100 \%$ & $0 \%$ & N.R. \\
\hline Time window & $0-6 \mathrm{~h}$ & $0-12 \mathrm{~h}$ & $0-6 \mathrm{~h}$ & $0-6 \mathrm{~h}$ & $0-8 \mathrm{~h}$ & $0-4.5 \mathrm{~h}$ & $0-5 \mathrm{~h}$ \\
\hline $\begin{array}{l}\text { Neurologic inclusion } \\
\text { criteria }\end{array}$ & N.A. & Barthel Index of $\geq 90$ & $\begin{array}{l}\text { mRS scores } \\
\text { of } 0-2\end{array}$ & $\begin{array}{l}\text { mRS scores } \\
\text { of } 0-1\end{array}$ & $\begin{array}{l}\text { mRS scores } \\
\text { of } 0-1\end{array}$ & & \\
\hline $\begin{array}{l}\text { Neuroimaging } \\
\text { techniques }\end{array}$ & $\mathrm{CT} / \mathrm{CTA}$ & $\begin{array}{l}\text { CT/CTA/CTA Multiphase } \\
\text { (for collaterals) }\end{array}$ & $\begin{array}{l}\text { CT/CTA/CTP } \\
\text { (for mismatch) }\end{array}$ & $\begin{array}{l}\text { CT/CTA/MRA/ } \\
\text { MRP/CTP } \\
\text { (for infarct core) }\end{array}$ & $\begin{array}{l}\text { CT/ } \\
\text { CTA(MRA/DSA) }\end{array}$ & $\mathrm{CT} / \mathrm{CTA}$ & $\mathrm{CT} / \mathrm{CTA}$ \\
\hline $\begin{array}{l}\text { Large artery } \\
\text { occlusion }\end{array}$ & CTA & CTA & CTA or MRA & CTA or MRA & CTA or MRA & CTA & CTA or MRA \\
\hline Affected arteries & $\begin{array}{l}\text { TICA, M1, M2, } \\
\mathrm{A} 1, \mathrm{~A} 2\end{array}$ & TICA, M1 & TICA, M1, M2 & TICA, M1, M2 & TICA, M1 & MCA & $\begin{array}{l}\text { ICA, M1, TB, } \\
\mathrm{M} 2\end{array}$ \\
\hline Infarct core/perfusion & N.R. & $\begin{array}{l}\text { NCCT, CBV or CBF } \\
\text { ASPECTS } \geq 6\end{array}$ & $\begin{array}{l}\text { Core }^{\psi}<70 \mathrm{ml} \\
(>1.2)^{¥}\end{array}$ & $\begin{array}{l}\text { Core } \Phi<50 \mathrm{ml} \\
(>1.8)^{*} \mathrm{NCCT} \\
\text { ASPECTS } \geq 6\end{array}$ & $\begin{array}{l}\text { NCCT ASPECTS } \\
\geq 7 \text { DWI } \\
\text { ASPECTS } \geq 6\end{array}$ & $\begin{array}{l}\text { Clot } \\
\text { length } \geq \\
8 \mathrm{~mm}\end{array}$ & N.R. \\
\hline Collateral status & N.R. & Good/Moderate & N.R. & N.R. & N.R. & N.R. & N.R. \\
\hline $\begin{array}{l}\text { Median stroke onset } \\
\text { to groin puncture }\end{array}$ & $260 \min$ & $241 \mathrm{~min}$ & $210 \min$ & $224 \min$ & $269 \mathrm{~min}$ & $226 \mathrm{~min}$ & $255 \min$ \\
\hline $\begin{array}{l}\text { Baseline NIHSS } \\
\text { [Median (IQR)]; } \\
\text { CG vs IA }\end{array}$ & $\begin{array}{l}18(14-22) \\
\operatorname{vs} 17(14-21)\end{array}$ & $\begin{array}{l}17(12-20) \text { vs } \\
16(13-20)\end{array}$ & $\begin{array}{l}13(9-19) \text { vs } 17 \\
(13-20)\end{array}$ & $\begin{array}{l}17(13-19) \text { vs } \\
17(13-20)\end{array}$ & $\begin{array}{l}17(12-19) \text { vs } \\
17(14-20)\end{array}$ & N.R. & $\begin{array}{l}17(13-20) \text { vs } \\
18(15-21)\end{array}$ \\
\hline $\begin{array}{l}\text { Median ASPECTS (\%); } \\
\text { CG/IA }\end{array}$ & $9 / 9$ & $9 / 9$ & $\mathrm{NR} / \mathrm{NR}$ & $9 / 9$ & $8 / 7$ & N.R. & N.R. \\
\hline $\begin{array}{l}\text { Patients Receiving } \\
\text { IV-rtPA (\%); CG/IA }\end{array}$ & $91 / 87$ & 79/73 & $100 / 100$ & $100 / 100$ & $78 / 68$ & $100 / 100$ & $100 / 100$ \\
\hline \multicolumn{8}{|l|}{ STUDY OUTCOMES } \\
\hline Primary Outcomes & $\begin{array}{l}\text { Shift in mRS } \\
\text { at } 90 \text { days }\end{array}$ & $\begin{array}{l}\text { Shift in } \mathrm{mRS} \text { at } \\
90 \text { days }\end{array}$ & $\begin{array}{l}\text { Reduction in perfusion } \\
\text { lesion volume; } \\
\text { NIHSS reduction } \\
\geq 8 \text { pointsor mRS score } \\
\text { of } 0-1 \text { at day } 3\end{array}$ & $\begin{array}{l}\text { Distribution of } \\
\text { mRS at } 90 \text { days; } \\
\% \text { mRS } 0-2 \\
\text { at } 90 \text { days }\end{array}$ & $\begin{array}{l}\text { Shift in mRS } \\
\text { at } 90 \text { days }\end{array}$ & $\begin{array}{l}\text { Shift in } \\
\mathrm{mRS} \text { at } \\
90 \text { days }\end{array}$ & $\begin{array}{l}\text { Shift in mRS } \\
\text { at } 90 \text { days }\end{array}$ \\
\hline $\begin{array}{l}\mathrm{mRS}(0-2) \text { at } 90 \\
\text { days \%; CG vs IA }\end{array}$ & $\begin{array}{l}19.1 \text { vs } 32.6 \\
P<0.05\end{array}$ & 29.3 vs $53, P<0.001$ & 40 vs $70, P=0.001$ & $\begin{array}{l}35.5 \text { vs } 60.2 \\
P<0.001\end{array}$ & 28.2 vs 43.7 & 30.4 vs 38 & 42.1 vs 54.2 \\
\hline $\begin{array}{l}\text { Improvement in mRS } \\
0-2 \text { at } 90 \text { days }\end{array}$ & $13.5 \%$ & $23.7 \%$ & $31.4 \%$ & $24.7 \%$ & $15.5 \%$ & $7.6 \%$ & $12.1 \%$ \\
\hline $\begin{array}{l}\text { sICH risk (\%); } \\
\text { CG vs } I A, P\end{array}$ & $\begin{array}{l}6.4 \text { vs } 7.7 \\
P>0.05\end{array}$ & 2.7 vs $3.6, P>0.05$ & 5.7 vs $0, P>0.05$ & $\begin{array}{l}3.1 \text { vs } 0 \\
P=0.12\end{array}$ & $\begin{array}{l}1.9 \text { vs } 1.9 \\
P>0.05\end{array}$ & $\begin{array}{l}11.3 \text { vs } \\
10.9\end{array}$ & $\begin{array}{l}2 \text { vs } 2 \\
P=0.71\end{array}$ \\
\hline $\begin{array}{l}\text { Parenchymal Hematoma } \\
\text { Risk (\%); CG/IA }\end{array}$ & 6 vs 6 & 2.0 vs 4.8 & 8.6 vs 11.4 & N.R. vs N.R. & 5.8 vs 5.8 & N.A. & $\begin{array}{l}9.45 \text { vs } 13.8 \\
P=0.53\end{array}$ \\
\hline
\end{tabular}


Table 4 Comparison of baseline characteristics and outcome measures of the recent endovascular trials $[27,194,286]$ (Continued)

\begin{tabular}{|c|c|c|c|c|c|c|c|}
\hline Trials & MR CLEAN [110] & ESCAPE [111] & EXTEND-IA [76] & $\begin{array}{l}\text { SWIFT PRIME } \\
{[112]}\end{array}$ & REVASCAT [113] & $\begin{array}{l}\text { THERAPY } \\
{[128]}\end{array}$ & $\begin{array}{l}\text { THRACE } \\
{[127]}\end{array}$ \\
\hline $\begin{array}{l}\text { Mortality (\%); CG vs } \\
\text { IA, P }\end{array}$ & $\begin{array}{l}22.1 \text { vs } 21 \\
P>0.05\end{array}$ & 19 vs $10.4, P=0.04$ & 20 vs $8.6, P>0.05$ & $\begin{array}{l}12.4 \text { vs } 9.2 \\
P>0.05\end{array}$ & $\begin{array}{l}15.5 \text { vs } 18.4 \\
P=0.06\end{array}$ & 23.9 vs 12 & $\begin{array}{l}13 \text { vs } 12 \\
P=0.70\end{array}$ \\
\hline $\begin{array}{l}\text { Decrease in mortality } \\
\text { at } 90 \text { days }\end{array}$ & $1.1 \%$ & $8.6 \%$ & $11.4 \%$ & $3.2 \%$ & $-2.9 \%$ & $11.9 \%$ & $1 \%$ \\
\hline \multicolumn{8}{|c|}{ Complete recanalization rates } \\
\hline mTICI Score 2b/3 & $58.7 \%$ & $72.4 \%$ & $86.2 \%$ & $88.0 \%$ & $65.7 \%$ & N.R. & N.R. \\
\hline $\begin{array}{l}\text { Complete recanalization } \\
\text { based on neuroimaging } \\
24-27 \text { h later; CG vs IA }\end{array}$ & $\begin{array}{l}68 / 207(33 \%)^{\mathrm{a}} \text { vs } \\
141 / 187(75 \%)^{\mathrm{a}}\end{array}$ & N.A. vs N.A. & $\begin{array}{l}15 / 35(43 \%)^{\mathrm{a}} \text { vs } \\
33 / 35(94 \%)^{\mathrm{a}}\end{array}$ & $\begin{array}{l}21 / 52(40 \%)^{\mathrm{b}} \text { vs } \\
53 / 64(83 \%)^{\mathrm{b}}\end{array}$ & N.A. vs N.A. & N.A. & N.A. \\
\hline $\begin{array}{l}\text { Brain infarction } \\
\text { volume at } 24 \text { hc } \\
\text { (mean, } 95 \% \text { Cl); CG vs } \\
\text { IA, P }\end{array}$ & $\begin{array}{l}79 \mathrm{~mL}(34-125) \\
\text { vs } 49 \mathrm{~mL}(22-96) \\
P<0.01\end{array}$ & N.A. vs N.A. & N.A. vs N.A. & $\begin{array}{l}35 \mathrm{~mL}(0-407) \\
\text { vs } 32 \mathrm{~mL} \\
(0-503), P=0.09\end{array}$ & $\begin{array}{l}39 \mathrm{~mL}(12-87) \text { vs } \\
16 \mathrm{~mL}(8-59) \\
P=0.02\end{array}$ & N.A. & N.A. \\
\hline NNT & 7.1 & 4.2 & 3.2 & 4.0 & 6.3 & 13.2 & 8.3 \\
\hline
\end{tabular}

IQR Interquartile range; TICA Terminal internal carotid artery (Carotid T/L); M1 and M2 Branches of the MCA; A1 and A2 Branches of the ACA; $m$ TICI Modified Thrombolysis in Cerebral Infarction; mRS Modified Rankin Scale; N.R. Not required; N.S. Not significant; N.A. Not available; CTA Computed tomography angiography; NCCT Non-contract computed tomography; CBV Cerebral blood volume; CBF Cerebral blood flow; MRA Magnetic resonance angiography; ASPECTS Alberta Stroke Program Early CT score; CG Control group; IA Intervention arm; IAT Intra-arterial therapy; TB Upper third of the basilar artery; MCA Middle cerebral artery; M2 Insular portion of the MCA; M1 Proximal portion of the MCA; ET Endovascular Thrombectomy; MT Mechanical thrombectomy; ESCAPE Endovascular Treatment for Small Core and Anterior Circulation Proximal Occlusion With Emphasis on Minimizing CT to Recanalization Times; EXTEND-IA Extending the Time for Thrombolysis in Emergency Neurological Deficits—Intra-Arterial; MR CLEAN Multicentre Randomized Clinical Trial of Endovascular Treatment for Acute Ischemic Stroke in the Netherlands; NIHSS National Institutes of Health Stroke Scale; REVASCAT Randomized Trial of Revascularization with Solitaire FR Device Versus Best Medical Therapy in the Treatment of Acute Stroke Due to Anterior Circulation LVO Presenting within $8 \mathrm{~h}$ of Symptom Onset; SWIFT PRIME Solitaire with the Intention for Thrombectomy as Primary Endovascular Treatment; NNT Number needed to treat for benefit (mRS score 0-2); THRACE Mechanical thrombectomy after intravenous alteplase versus alteplase alone after stroke

${ }^{\sharp}$ Target mismatch ratio; ${ }^{\lambda}$ Sum of median of parameters; ${ }^{\top}$ The ischemic core was assessed by MRI or CT; ${ }^{4}$ The ischemic core was defined by regional cerebral blood flow on CT perfusion or diffusion-weighted imaging; ${ }^{a}$ Recanalization shown in brain CTA/MRA at $24 \mathrm{~h}$;

${ }^{\mathrm{b}}$ Reperfusion shown in brain CT perfusion/MR perfusion at $27 \mathrm{~h}$; ${ }^{\mathrm{C}}$ Brain infarction volume at $24 \mathrm{~h}$ after treatment measured with CT in MR CLEAN trial and with CT or MRI in SWIFT PRIME and REVASCAT trials

With the Intention for Thrombectomy as Primary Endovascular Treatment of Acute Ischemic Stroke) [112], EXTEND-IA (Extending the Time for Thrombolysis in Emergency Neurological Deficits-Intra-arterial) [76], and REVASCAT (Randomized Trial of Revascularization with Solitaire FR Device vs Best Medical Therapy in the Treatment of Acute Stroke Due to Anterior Circulation Large Vessel Occlusion Presenting within 8 h of Symptom Onset) [113], it is now accepted that the combined treatment with second-generation stent retriever MT devices and IV-rtPA within $6 \mathrm{~h}$ after stroke onset is superior to standard medical therapy (with IV-rtPA alone) for AIS caused by a proximal large artery occlusion of the anterior circulation [114].

Immediately after the announcement of the MR CLEAN results [110], the other four trials were terminated prematurely for interim analysis. The results of these trials were then published in quick succession in late 2014 and early 2015. The number needed to treat (NNT) for these five trials ranged from a minimum of three (EXTEND-IA) to a maximum of 7.4 (MR CLEAN). The success of these trials has revolutionised stroke therapy. However, given that only trained neuro-interventionists can perform the MT procedures, stroke care facilities should expeditiously work on integrating MT with standard care, to minimise the time required for imaging and preoperative preparation needed for this therapy [115]. A recent metaanalysis, based on a pooled analysis of 1287 patients, published by the Highly Effective Reperfusion evaluated in Multiple Endovascular Stroke Trials (HERMES) collaboration, showed that endovascular MT added to the best medical therapy more than doubles the odds of a higher rate of (a) functional independence (mRS score at 90 days of 0 to 2 ) (46\% vs. $27 \%$, odds ratio $2.35,95 \%$ CI $1.85-2.98$ ) [116], and (b) significantly reduced disability (improvement of $\geq 1$ points on the mRS at 90 days) (adjusted OR 2.49 , 95\% CI 1.76-3.53) compared with best medical therapy alone in AIS patients with large vessel occlusion in the anterior circulation. The rates of symptomatic ICH or 90-day mortality were also not significantly different between the endovascular MT and control groups [117]. Another recent meta-analysis by the same HERMES collaboration has suggested that the endovascular MT plus medical therapy is beneficial up to $7.3 \mathrm{~h}$ after the onset of stroke [118]. Recently published DAWN trial has shown benefit of MT for an extended time window of 6-24 h [119]. To sum up, these studies make a convincing case for the administration of early thrombectomy using second-generation stent retrievers for limiting post-stroke disability in patients with large vessel occlusion in the anterior circulation. They also reinforce the importance of early treatment based on an inverse association between 
time to endovascular reperfusion and better functional outcome [118].

\section{Clinical trials with first-generation devices}

Prior to MR CLEAN trial, three endovascular trials, using mainly first generation MT devices during 2004 and 2012, including MR RESCUE (Mechanical Retrieval and Recanalization of Stroke Clots Using Embolectomy) [120], the IMS (Interventional Management of Stroke) III [121], and the SYNTHESIS Expansion (Intra-arterial vs. Systemic Thrombolysis for Acute Ischemic Stroke) [83] failed to demonstrate any functional benefit for intra-arterial treatment in AIS. The results of these trials, which were published in 2013, raised concerns regarding the efficacy of endovascular MT in large vessel occlusion. Potential causes for this lack of effect were suggested including: (a) the three trials used old-generation devices with reduced recanalization efficacy in comparison to the later generation devices which were used in the MR CLEAN trial, and (b) previous trials did not use vessel occlusion as an eligibility criterion because radiological confirmation of large artery occlusion was lacking due to limited availability of CTA at that time [122-124].

\section{Phase 2 clinical trials with second-generation devices}

The second-generation MT devices, Solitaire flow restoration device and Trevo retriever, are based on stent retrievers, which are very effective in capturing thrombus and produce excellent vessel recanalization. Two phase 2 clinical trials, SWIFT (Solitaire Flow Restoration Device Versus the Merci Retriever in $\mathrm{Pa}$ tients with Acute Ischemic Stroke) and TREVO 2 (Trevo Versus Merci Retrievers for Thrombectomy Revascularization of large vessel occlusion in Acute Ischemic Stroke), demonstrated that stent retrievers achieved better clinical outcomes by increasing recanalization of large artery occlusions, than the firstgeneration Merci Retriever and Penumbra System devices [93, 94, 125, 126]. The SWIFT study assigned eligible patients to receive MT treatment with either MERCI device $(n=55)$ or Solitaire stent retriever $(n=$ 58). The Solitaire group showed significantly improved recanalization, as defined by a Thrombolysis in Myocardial Infarction (TIMI) Score of two (partial recanalization) or three (total recanalization) (61\% vs. $24 \%, P<0.0001)$, and better functional outcomes $(58 \%$ vs. $33 \%, P<0.0001)$ than the MERCI group. The TREVO trial produced similar outcomes, with the TREVO device achieving better recanalization (86\% vs. $60 \%, P<0.0001$ ), defined by Thrombolysis in Cerebral Infarction (TICI) score of 2 or 3 , and improved long-term clinical outcomes $(40 \%$ vs. $22 \%, P<0.013)$ in comparison to the first generation Merci retriever. No difference in the incidence of symptomatic intracerebral haemorrhage (sICH) was reported between TREVO and Merci groups.

\section{Phase 3 clinical trials with second-generation devices}

MR CLEAN was a Dutch endovascular trial that assigned 500 patients to the intervention arm (IAT with standard therapy; $n=233$ ) and the control arm (standard therapy; $n=267$ ) alone [110]. All patients in the control arm received IV-rtPA. Endovascular procedures were performed using second-generation stent retrievers. Stent retrievers were used in $81.5 \%(190 /$ 233) of patients who received IA treatment. MR CLEAN included patients presenting within $6 \mathrm{~h}$ of stroke onset, aged 18 and above, with a minimum NIHSS score of two, and large artery occlusion confirmed on CTA. MR CLEAN trial did not have an upper age threshold for eligibility unlike previous trials, where patients above 80 years were excluded. Moreover, an Alberta Stroke Program Early CT Score (ASPECTS) score was not used in the randomization of patients. Patients who received MT and standard treatment (intervention arm) showed good recanalization (defined by TICI score of $2 \mathrm{~b} \quad(>50 \%$ recanalization) or 3) in 59\% (115/196) of the patients. This arm also demonstrated improvement in good outcome at 90 days $(32.6 \%$ vs. $19.1 \%$; OR $=1.67$ [95\% CI 1.21 to $2.3]$ ), and a significant decrease in brain infarct at $24 \mathrm{~h}(49 \mathrm{~mL}$ vs. $79 \mathrm{~mL}, P<0.01)$ in comparison to the standard medical therapy group. The number need to treat (NNT) was 7.1. No significant difference in the occurrence of $\mathrm{sICH}$ or death was found in between the two groups.

The Endovascular Treatment for Small Core and Proximal Occlusion Ischemic Stroke (ESCAPE) trial randomised 315 patients, 150 in the control arm and 160 in the MT arm, for an extended therapeutic time window of $0-12 \mathrm{~h}$ [111]. Strict inclusion criteria including NIHSS $>5$, pre-morbid Barthel index of 90 and above, large artery occlusion confirmed on $\mathrm{CT}$ angiography (CTA), ASPECTS score of $\geq 6$, and good or moderate leptomeningeal collateral status on CTA was applied. In comparison to previous trials, ESCAPE used CTA, preferably multiphase CTA, to select patients based on the neuroimaging assessment of the site of occlusion and collateral status. The trial was unique given the pioneering enrollment goals, including door to puncture times of less than $60 \mathrm{~min}$, and door to recanalization time of fewer than $90 \mathrm{~min}$. Given the trial was stopped following the announcement of MR CLEAN results, an interim analysis showed good recanalization rates $(72 \%)$, defined by TICI score of $2 \mathrm{~b}$ or 3 , and significantly better functional outcomes in the MT group vs. the standard therapy $(53 \%$ vs. $29 \%, \quad P<0.001)$. Concerning safety endpoints, MT showed reduced mortality rate $(10 \%$ vs. 
$19 \%, P=0.04)$, and comparable sICH rates $(3.6 \%$ vs. $2.7 \%, P>0.05)$ vs. the control group.

The SWIFT-PRIME trial boasted the maximum number $(n=39)$ of recruitment centres spanning the United States and Europe [112]. Between 2012 and 2014, 196 patients presenting within $6 \mathrm{~h}$ of stroke onset were enrolled and assigned to treatment groups: MT (using Solitaire FR stentriever) plus standard therapy, IV-rtPA $(n=98)$, or standard therapy alone $(\mathrm{n}=98)$. For randomization, patients with NIHSS scores between 8 and 30, aged between 18 and 80 years, and a premorbid score of $\mathrm{mRS}<1$ were considered. The SWIFT-PRIME study used neurovascular angiography imaging (CTA/ magnetic resonance angiography (MRA)) to identify patients with large artery occlusion prior to randomization. SWIFT PRIME introduced an automated post-processing imaging pipeline software for penumbra profiling (RAPID), although its use was not mandatory or part of the inclusion criteria. Infarct core volume was estimated from CT Perfusion (CTP) using RAPID. A cut-off of infarct core volume of $>50 \mathrm{~mL}$ on CTP was used to exclude patients. The ischemic core was defined by regional cerebral blood volume (CBV) or delayed time to peak (TTP) of the residual function. Moreover, patients with baseline ASPECTS score of less than six were excluded. The SWIFT PRIME study achieved the highest recanalization (defined by modified TICI score of $2 \mathrm{~b}$ or 3 ) rate of $88 \%$ for the MT arm in comparison to the other four contemporary endovascular trials. The MT group showed 24.7\% improvement in the functional outcome at 90 days (mRS $0-2$ : MT $60.2 \%$ vs standard therapy $35.5 \%, P<0.001)$. Efficacy of MT in SWIFTPRIME (60.2\%) was higher than MR CLEAN (32.6\%) and ESCAPE (53\%) trials. No significant group differences in sICH risk ( $0 \%$ vs $3 \%, P=0.12)$, or 90 -day mortality ( $9 \%$ vs $12 \%, P>0.05)$ were found.

EXTEND-IA was an Australasian trial involving 10 centres across Australia and New Zealand that enrolled 70 patients who were randomised to receive IV-rtPA alone, or MT using Solitaire FR stentriever plus IV-rtPA [76]. Like the SWIFT PRIME, EXTEND-IA also required administration of MT and IV-rtPA within 6 and $4.5 \mathrm{~h}$ of onset of stroke symptom, respectively. However, unlike other trials, there was no restriction on stroke severity as a criterion for patient inclusion. Moreover, age or ASPECTS score was not part of criteria for randomization. Premorbid functional status of mRS 0 to 2 was required for inclusion in the study. With regards to neuroimaging selection criteria, CTP for detection of favourable penumbra using RAPID software similar to SWIFT PRIME (CTP core volume less than $70 \mathrm{~mL}$ or mismatch ratio greater than 1.2), and CTA for large artery occlusion diagnosis were used to randomise patients. The primary outcome for the EXTEND-IA study was a reduction in the NIHSS score of 8 or higher, a score of 0 or 1 on mRS at 90 days, or reduction in perfusion lesion volume. EXTEND-IA showed the highest improvement in functional outcome at 90 days in comparison to the other four-endovascular trials (31.4\%), and recanalization rate (86.2\%) comparable to SWIFT PRIME. The number needed to treat (NNT) was the lowest for EXTEND-IA (NNT: 3.2 (EXTEND-IA) vs. 7.1 (MR PRIME) vs. 4.2 (ESCAPE) vs. 4 (SWIFTPRIME) vs. 6.3 (REVASCAT)). The MT arm showed significantly improved functional outcome compared to the standard therapy arm $(70 \%$ vs. $40 \%, P=0.001)$. The investigators reported no significant differences in risk of sICH and mortality between the two groups.

REVASCAT was a Spanish trial involving four tertiary hospitals that enrolled 206 AIS patients presenting within $8 \mathrm{~h}$ of the symptom onset randomised to receive MT with the Solitaire FR plus standard medical therapy $(n=103)$ or standard medical therapy including IV-rtPA for eligible patients $(n=103)$ [113]. Clinical inclusion criteria included age between 18 and 80 years, NIHSS of 6 or more, and a pre-treatment mRS score of 0 to 1 . Neuroimaging with CTA or MRA was used to select patients with large vessel occlusion. Moreover, only patients with ASPECTS scores of seven and above on NCCT or six and above on DWI MRI were included. Interestingly, the inclusion criteria were revised to age < 85 years and ASPECTS score of eight or above on NCCT after the enrollment of 160 patients. The REVASCAT trial showed $65.7 \%$ recanalization for patients in MT arm, and a significant reduction in brain infarction volume at $24 \mathrm{~h}(16 \mathrm{~mL}$ vs. $39 \mathrm{~mL}, P=0.02)$ vs. standard medical therapy. No significant differences were noted in the rates of $\mathrm{sICH}(1.9 \%$ vs. $1.9 \%, P>0.05)$ or mortality (18.4 vs. $15.5, P=0.06$ ) between the two groups. Patients in the MT arm were more likely to have a better functional outcome at 90 days ( $43.7 \%$ vs. $28.2 \%$; OR $2.1,95 \%$ CI 1.1 to 4 ).

In summary, these five-endovascular randomised controlled trials have consistently shown that MT significantly improves reperfusion and functional outcome at 90 days without an increase in mortality compared to patients receiving standard medical therapy. Use of advanced imaging features such as ASPECTS scale or perfusion imaging may assist in selecting patients who are most likely to benefit from a combined approach. Advanced imaging helps to differentiate between salvageable tissue and irreversibly dead core. Unfortunately, selection of patients using advanced imaging excludes many patients who may otherwise have received intra-arterial treatment.

Two new clinical trials, the Trial and CostEffectiveness Evaluation of Intra-arterial Thrombectomy in Acute Ischemic Stroke (THRACE) [127] and the Assess the Penumbra System in the Treatment of Acute Stroke (THERAPY) [128], have addressed these 
shortcomings by keeping selection criteria to a minimum except for the use of angiographic technique such as CTA or MRA to localize and confirm the arterial occlusion. The THRACE trial, conducted across 26 centres in France, included 336 patients, aged 18 to 80 years and NIHSS score ranging between 10 and 25, presenting within $5 \mathrm{~h}$ of symptom onset with moderate to a severe stroke caused by the large artery occlusion of the anterior circulation (radiologically confirmed on CTA), out of which 195 received IVT, and 141 received combined IVT and MT treatment, without a selection based on advanced imaging-based criteria. Combined IV-rtPA and MT provided a higher rate of functional outcome at 90 days $(54.2 \%$ vs. $42.1 \%)$. No significant differences in mortality and sICH risks were noted between the MT and control arms. The THERAPY trial, undertaken across four centres in the United States, selected patients with AIS presenting within $4.5 \mathrm{~h}$ of symptom onset who have evidence of large clot burden (clot length $\geq 8 \mathrm{~mm}$ ) in the anterior circulation [128]. CTA was used to identify patients with large vessel occlusion. Patients with NIHSS score of eight and above and age between 18 and 85 years were included for randomization. Patients were then treated with both combined IV-rtPA and IAT with the Penumbra aspiration system (a new technique of aspiration thrombectomy) or with the IV-rtPA alone. The results showed a positive trend, though not significant, of aspiration thrombectomy towards better functional outcomes (38\% vs. 30.4\%). Interestingly, the intervention arm showed a considerable reduction (11.9\%) in mortality (mortality in intervention arm vs. control arm: $12 \%$ vs. $23.9 \%)$. No significant difference in sICH risk was observed (10.9\% vs. $11.3 \%)$.

To sum up, MT has a number of advantages over systemic thrombolysis [87]: (a) MT yields higher rates of revascularization, and reduced rates of long-term functional dependence, in a select group of AIS patients with large vessel occlusion, compared to IVT alone $[78,79,129-131]$, (b) MT extends the therapeutic time-window for acute intervention up to $24 \mathrm{~h}$ from stroke onset, beyond the $4.5 \mathrm{~h}$ restricted time window for IVT, which is applicable to only a small number of AIS patients [74, 119, 132-134], (c) MT presents a viable alternative to patients with large vessel occlusion who respond poorly, vis a vis poor recanalization rates and risk of haemorrhage, with systemic therapy [134], or those who have contraindications to the use of systemic thrombolysis, and (d) MT is efficient in dissolving clots which are resistant to enzymatic degradation, such as old and large clots with hardened fibrin and cross-linked thrombi containing calcium and cholesterol crystals, which have poor recanalization yields with systemic thrombolysis $[93,133,135]$.

\section{Combined intravenous and endovascular therapy: A} multimodal reperfusion therapy (MMRT) approach

The idea behind combining intravenous and endovascular approaches, also called bridge therapy [136-141] or multimodal reperfusion therapy (MMRT), is to take advantage of best of both approaches by allowing fast and early access to IV-rtPA within the first $4.5 \mathrm{~h}$ of stroke onset, and superior recanalization rates even for delayed time windows beyond $4.5 \mathrm{~h}$ using endovascular therapy [142]. Notably, the Interventional Management of Stroke (IMS) I [143] and II [144] trials were conducted to investigate the feasibility and safety of combined interventions: low dose, $0.6 \mathrm{mg} / \mathrm{kg}$, IV-rtPA followed by intra-arterial rtPA within $3 \mathrm{~h}$ since stroke onset, to recanalization of AIS. The bridge IV and IA therapy were not significantly different from the IV-rtPA alone as both yielded similar proportions of $\mathrm{ICH}$, rates of mortality and mRS at 90 days. The subsequent IMS III trial also found no additional benefit of bridge therapy compared with IV-rtPA alone [145]. One of the important factors that may have played a role in these results is the time delay (approximately $32 \mathrm{~min}$ ) between the IV-rtPA and initiation of intra-arterial therapy [121, 143]. Unlike the neutral results of IMS III trial, a recent meta-analysis reported a significantly strong association of combined intravenous-IA thrombolysis over IV fibrinolysis alone with favourable outcome, reduced mortality, and improved recanalization rates [146].

The Stent-Assisted Recanalization in Acute Ischemic Stroke (SARIS) trial, conducted to investigate the safety of intracranial stent deployment within $8 \mathrm{~h}$ of stroke onset, demonstrated expeditious recanalization, and favourable outcomes at 30 and 180 days clinical followup $[147,148]$. Stent deployment averts arterial reocclusion and thrombus reformation in cases with partial embolectomy or arterial stenosis. The utility of selfexpanding stents (SES) has been explored. The SES yields dramatically high recanalization rate of up to $90 \%$ by a combination of balloon angioplasty and stent implantation [147]. Undoubtedly, the bridge endovascular therapy using MT, intracranial stent deployment, and IV thrombolysis allows an extended time window, and therefore a higher proportion of revascularisations and improved clinical outcomes in AIS patients with large artery occlusion of anterior circulation [22].

A number of MMRT approaches including combined IV-rtPA and IA-tPA [136-138, 140, 141, 149], IV-tPA followed by multimodal endovascular therapy [150], combined IA thrombolytics and glycoprotein IIb/IIIa inhibitors [151], IA administration of microbubbles and continuous 2-MHz ultrasound insonation [139], IA-tPA followed by stenting $[152,153]$ or angioplasty or both $[154,155]$, IA urokinase and mechanical clot disruption following failed IV-tPA [156], MT using balloon 
angioplasty and adjuvant systemic thrombolysis (IV-tPA, IA urokinase, both IV-tPA and IA-urokinase, and IV and/or IA eptifibatide) [157], MT (MERCI retrieval, angioplasty/stent) with or without adjunctive IA-tPA/ Urokinase [158], MT using clot retrievers and angioplasty with intracranial or extracranial stenting [151], have demonstrated considerably improved recanalization, reperfusion and clinical outcomes [140, 150, 151, 154, 155, 159, 160]. Gupta et al. (2011) reported significantly higher recanalization rates for multimodal therapy (MT using intracranial stenting in conjunction with IV/ IA thrombolysis) $(74 \%[435 / 584])$ in comparison to pharmacologic treatment only $(61 \%[160 / 264])$, or MT only $(63 \%$ [173/274] ) in a large retrospective cohort of 1122 AIS patients involving the anterior circulation who received IAT within $8 \mathrm{~h}$ of stroke onset [153].

Drawing from the success of these studies, an endovascular MMRT approach using pharmacological thrombolytics (IA lytic drugs), in conjunction with MT using mechanical devices such as clot retrievers, angioplasty with stenting, aspiration devices, and stent retrievers is being increasingly adopted as the treatment of choice for stroke due to large vessel occlusion [153, 159]. Endovascular MMRT or bridge therapy offers a safe alternative for AIS patients, with large intracranial vessel occlusion, who fail to reperfuse with systemic thrombolytic drugs.

\section{Role of collaterals in penumbral sustenance and recanalization}

Recanalization is positively associated with favourable clinical outcome and increased survival rates in acute ischemic stroke [39, 40, 161-165]. A meta-analysis of 53 studies encompassing 2066 patients reported strong association of recanalization with the good functional outcome (OR 4.43, 95\% CI 3.32 to 5.91), and reduced mortality (OR $0.24,95 \%$ CI 0.16 to 0.35 ) at 3 months in AIS [146]. The rate of recanalization classified based on intervention: spontaneous, IV fibrinolytic, intra-arterial fibrinolytic, combined IV and IA thrombolysis or MT was 24.1, 46.2, 63.2, 67.5, 83.6\%, respectively. Early recanalization is associated with rapid clinical improvement in some patients [166]. However, despite early recanalization, some patients who are otherwise unresponsive to treatment over short-time follow-up, may show delayed recovery or favourable long-term outcome suggesting the possibility of an "ischemic stunning" or "stunned brain" syndrome [167]. Recanalization enables restoration of cerebral blood flow to the hypoperfused brain region surrounding the infarcted 'core'. This area of the brain with reversible ischemia surrounding the infarcted core is called ischemic penumbra [168]. Animal studies have indicated that considerable salvage of penumbral tissue is possible on the restoration of blood flow to the hypoperfused brain area, even after $24 \mathrm{~h}$, irrespective of time of reperfusion [169, 170]. From a pathophysiological standpoint, the survival of penumbra, independent of time, for up to $48 \mathrm{~h}$ has been reported using a ligand that selectively binds to hypoxic but viable tissue ([(18)F]fluoromisonidazole), and positron emission tomography (PET) on consecutive patients presenting within $48 \mathrm{~h}$ of AIS [171]. As expected, the penumbra reduces over time; it is observed in $90-100 \%$ of stroke patients in the first $3 \mathrm{~h}$ after stroke onset [172], 75-80\% of patients $6 \mathrm{~h}$ after stroke onset, and approximately $33 \%$ of patients $18 \mathrm{~h}$ after stroke onset [173].

Despite the success of endovascular procedures, a number of patient-specific factors may determine the response to treatment such as (a) collateral circulation [174-176], (b) site of vessel occlusion [48], (c) onset to angiographic reperfusion time [177-179], (d) hyperglycemia [180-182], and (c) location of cerebral ischemia $[174,183]$. In the case of cerebral ischemia, collaterals compensate for the sudden drop in CBF in the hypoperfused area by the maintenance of a continual blood supply to ischemic penumbra. For recanalization to translate into positive outcomes, adequate collaterals must delay the infarction of tissue until recanalization is achieved [184]. Collaterals can sustain the penumbra even in the absence of reperfusion or recanalization. According to a meta-analysis, good baseline collaterals were associated with favourable outcome at 90 days, decrease in the risk of symptomatic $\mathrm{ICH}$, and decrease in risk of death at 90 days in patients with AIS receiving endovascular treatment [176]. Good baseline collaterals have been found to be associated with $24 \mathrm{~h}$ perilesional hyperperfusion [185], good clinical outcome [176, 186-189], lower rates of symptomatic ICH and mortality [176], improved radiologic outcome [188], cortical infarct volume [190], good reperfusion [191], and stroke severity [191]. On the other hand, delayed-cortical vein filling was independently associated with reduced baseline collateral status in AIS [185]. Collateral grading is used to determine recanalization rate after endovascular reperfusion therapy $[175,192]$. Collateral pathophysiology may have predictive value, and patent collaterals may help boost reperfusion [193]. Some scales and grading tools are available for reliable and quick assessment of the patency of collaterals by visual examination of multiphase CTA [189].

\section{Limitations and unresolved questions of endovascular reperfusion therapy}

Despite the substantial advantages of MT, this is only offered to a limited number (5-10\%) of AIS patients [131]. Currently, vascular imaging such as CTA or MRA is not routinely performed at the time of presentation. The treating physician needs to make a rapid decision based on the vascular imaging (whether or not angiography shows a large vessel occlusion), assessment of ischemic penumbra (based on $\mathrm{CT}$ or $\mathrm{MR}$ perfusion 
imaging), time since the onset of stroke symptoms, along with other baseline clinical factors and previous history (such as significant past trauma, haemorrhage or stroke) $[90,127,194]$. The need for advanced imaging, especially CTA, implies that only a few select AIS patients would be suitable for MT. MT with current devices is not well suited for AIS with occlusions in distal locations and with penetrator occlusions due to difficulty in navigating with the catheter, increased risk of intraprocedural vessel perforation, and a higher risk of mortality [101, 195]. Also, patients with in situ intracranial atherothrombi (in situ atherosclerotic plaque with supervening thrombosis), may be more suited for balloon angioplasty and stenting over MT [101]. MT yields superior recanalization rates with occlusions of cardioembolic origin [196] or proximal aortocervical arterial source [101]. Delayed treatment may lead to further shrinking of salvageable penumbral tissue due to absence or insufficient reperfusion. MT is a highly specialized interventional procedure; as such, it is strongly recommended that MT be performed in a comprehensive stroke unit with a wellequipped neurointervention suite by an interventional neuroradiologist or an endovascular specialist with experience in the procedure, or a credentialed neurointerventionist along with a team of stroke neurologists, and nursing staff [197]. Lack of experienced practitioners (such as credentialed neuro interventionist, endovascular specialists) [197], along with logistic difficulties such as prehospital delays (e.g., prolonged transfer time to and from rural hospitals), and inter-facility transfers, make MT unlikely to be widely implemented. A comprehensive national and international stroke care policy needs to be adopted to address these logistical and other systemic deficiencies within the relevant healthcare systems.

In addition to the limitations of present reperfusion therapies in AIS settings, a number of unresolved questions or issues need to be addressed.

\section{Extending the time window of MT beyond $6 \mathrm{~h}$}

Evidence for efficacy and safety of endovascular reperfusion beyond $6 \mathrm{~h}$ is still insufficient given that no randomised trial has used this as an inclusion criterion. However, a recent meta-analysis has indicated the benefit of endovascular MT plus medical therapy up to $7.3 \mathrm{~h}$ after the symptom onset [118]. Some trials including the premise of the Diffusion and Perfusion Imaging Evaluation for Understanding Stroke Evolution (DEFUSE 3), the DWI or CTP Assessment With Clinical Mismatch in the Triage of Wake-Up and Late Presenting Strokes Undergoing Neurointervention (DAWN), the Perfusion Imaging Selection of Ischemic Stroke Patients for Endovascular Therapy (POSITIVE) and Imaging-Guided Patient Selection for Interventional Revascularization
Therapy (START) trials seek to extend the time to endovascular reperfusion. DEFUSE 3 selects AIS patients using penumbral mismatch on CTP or MRI who may benefit from MT between $6 \mathrm{~h}$ and $16 \mathrm{~h}$ post onset [198]. Similarly, the goal of the POSITIVE trial is to use appropriate imaging selection to improve stroke-related disability, and functional outcome in AIS patients treated with MT presenting between 6 to $12 \mathrm{~h}$ who are either ineligible for or refractory to IV-tPA treatment [199]. DAWN, which recruited patients in which treatment with Trevo MT was initiated within 6-24 h after stroke onset [200] [201], was terminated early after an interim analysis of the first 200 patients demonstrated a 73\% relative risk reduction in disability (48.6\% in MT group vs. $13.6 \%$ in control group). DAWN study has confirmed that advanced imaging based patient selection outweighs time-based decision making in acute ischemic stroke [119]. This has major implications for treatment in acute ischemic stroke given that DAWN showed efficacy over an extended time window from 6 to $24 \mathrm{~h}$ [202].

\section{General anaesthesia vs. conscious sedation}

The type of anaesthesia, whether general anaesthesia (GA) or conscious sedation, has implications for outcomes in AIS patients during and after endovascular treatment [203]. This has been a subject of ongoing debate given that several retrospective studies have hypothesised that GA may be associated with periprocedural hypotension that may cause poorer clinical outcome, despite the procedural advantages of GA [203-205]. A consensus is still missing over the anaesthetic management of AIS patients during IAT [206]. The MR CLEAN pre-trial study group found that non-GA was significantly associated with good clinical outcomes in AIS patients undergoing IAT [206]. Three randomized trials, Sedation vs Intubation for Endovascular Stroke Treatment (SIESTA) [207], the General or Local Anaesthesia in Intra-arterial Therapy (GOLIATH) [208], and the Sedation Versus General Anaesthesia for Endovascular Therapy in Acute Stroke (ANSTROKE) [209], aimed to investigate the impact of anaesthesia type on neurological outcome in IAT, and whether conscious sedation is the optimal anaesthesiologic management modality in endovascular stroke therapy $[122,210]$. ANSTROKE [211] and SIESTA [212, 213] have both recently demonstrated no advantage in neurological status at $24 \mathrm{~h}$ or 3 months for patients undergoing MT with conscious sedation.

\section{Posterior circulation stroke}

AIS in the posterior circulation is associated with poor prognosis with standard medical therapy (IVtPA) $[214,215]$. Basilar artery occlusion (BAO) is a 
form of posterior circulation stroke that results in higher rates of poor functional outcome and mortality if not recanalized $[214,216]$. A systematic analysis of 420 BAO patients treated with IVT (76) and IAT (344) found that without recanalization only $2 \%$ patients were likely to have good outcome [216]. Recanalization was more common in IAT-treated patients than those who received IVT (65\% (225/344) vs. $53 \%(40 / 76)$. The success of recanalization of acute BAO following IVT depends on thrombus length [45]. Another analysis on 592 BAO patients drawn from a prospective register also challenged the notion of unequivocal superiority of IAT over IV-tPA in BAO patients [217]. Interestingly, bridge therapies combining IAT using modern MT devices and IV-tPA have yielded good recanalization and improved survival rates for acute BAO [218-220]. Based on these findings, a multicenter randomized controlled trial, Basilar Artery International Cooperation Study (BASICS), was conceived, and is currently underway, to evaluate the efficacy of IAT plus standard medical treatment versus standard therapy alone in patients with acute BAO stroke [221, 222]. Recent studies have shown MT with the Solitaire FR device is associated with high recanalization rates and favourable outcome [223, 224].

\section{Minimising the delay to endovascular reperfusion}

Direct Transfer to an Endovascular Center Compared to Transfer to the Closest Stroke Centre in Acute Stroke Patients With Suspected Large Vessel Occlusion (RACECAT) is a prospective, randomized controlled trial which aims to evaluate the effectiveness of direct transfer to an endovascular stroke center based on identification of suspected large vessel occlusion in AIS patients using a prehospital screening tool, rapid artery occlusion evaluation (RACE) scale, in comparison to the transfer to the closest local stroke center [225]. The motivation behind this trial is to minimise the time to endovascular reperfusion. Triaging of AIS patients for their eligibility to IAT requires CT for determination of the presence of large artery occlusion. However, it may be possible to select patients based on nonimaging scales that can be easily applied without extensive training. Staff with emergency medical services (EMS) could be trained to use these scales (e.g., NIHSS, RACE) in screening AIS patients for their eligibility to receive reperfusion therapy.

In addition to the above issues, other treatment options such as the use of antithrombotic medications along with reperfusion therapy are also being explored. A phase III trial, Multi-Arm Optimisation of Stroke Thrombolysis [226], is investigating the efficacy of IV delivery of Argatroban and Eptifibatide in combination with rtPA in AIS. This strategy may be extended to patients who undergo MT. Some trials are currently underway or are in the planning phase to address the issues that limit the efficacy of endovascular reperfusion. A comprehensive list of ongoing and future trials is shown in Table 5.

\section{Conclusions, discussions, and future recommendations}

The approved treatment for acute ischemic stroke is reperfusion therapy using systemic thrombolysis or endovascular mechanical thrombectomy. The recent success of endovascular trials has revolutionised the way large artery occlusion stroke patients are managed. AHA/ASA has accordingly updated its guidelines for stroke care. The recommendation is to use MT with stent retriever in combination with standard therapy (IV-rtPA) in AIS patients, aged $\geq 18$ years; baseline ASPECTS score $\geq 6$, baseline NIHSS score $\geq 6$ with angiographically confirmed large vessel occlusion presenting within $6 \mathrm{~h}$ of symptom onset (Level 1A evidence) [227, 228]. The workflow algorithm detailing the standard of care for IV-tPA and mechanical thrombectomy in AIS patients is shown in Fig. 2 (algorithm has been updated keeping in consideration recently published DAWN study [119, 202]).

Endovascular therapy also provides an alternative to systemic thrombolysis for patients who fail to reperfuse with IV-rtPA or those who are not eligible for IVT due to restricted time-window, or those with unknown onset or "wake-up" stroke, or contraindications [153, 159, 215]. However, due to a shortage of neurointerventionists or endovascular specialists experienced in the procedure [197], procedural complexity, high costs, pre-hospital delays, inter-facility transfers, and a limited number of institutions that offer endovascular treatment, only a select number of patients will likely be offered this therapy [229]. Future efforts to shorten the endovascular procedural time, build infrastructure to provide MT, and increase access to endovascular facilities are required [27]. Comprehensive stroke centers with access to IV and IA techniques, trained stroke neurointerventionists, imaging-guided treatment workflow, and access to advanced neurosurgical support will pave the way for high-end stroke care delivery. Meanwhile, given the present limitations, careful selection of patients is crucial to maximize the gain for appropriate patients. It has been suggested that patients with angiographically confirmed proximal large vessel occlusion with a viable penumbra on MRI and NIHSS $>18$, within 8 and 24 h of stroke onset in the anterior and posterior circulation respectively, should be given endovascular MMRT [159]. Other authors 
Table 5 List of ongoing and upcoming trials aimed to address the issues concerning the endovascular treatment of acute ischemic stroke

\begin{tabular}{lll}
\hline Trial & $\begin{array}{l}\text { Time } \\
\text { window }\end{array}$ & Purpose \\
\hline $\begin{array}{lll}\text { RACECAT } \\
\text { [225] }\end{array}$ & $0-8 \mathrm{~h}$ & $\begin{array}{l}\text { Triage of the acute LVO on direct } \\
\text { transfer to EVT-SC bypassing LSC } \\
\text { vs. transfer to the LSC accordin } \\
\text { to the current stroke protocol. }\end{array}$ \\
& & \\
& & \\
DEFUSE 3 & $6-16 \mathrm{~h}$ & $\begin{array}{l}\text { Benefit of carefully selected } \\
\text { patients with target mismatch } \\
\text { [198] }\end{array}$ \\
& & $\begin{array}{l}\text { and MCA (M1 segment) or ICA } \\
\text { occlusion using CT/MR within } \\
\text { 6-16 h treated with MT plus } \\
\text { standard therapy v. Standard } \\
\text { therapy alone. }\end{array}$
\end{tabular}

DAWN 6-24 $\mathrm{h} \quad$ MT using the Trevo Retriever with $[119,200]$

POSITIVE 6-12 h $\quad \begin{aligned} & \text { To determine the safety and } \\ & \text { efficacy of IAT in AIS patients } \\ & \text { Ineligible for or refractory to } \\ & \text { IV-rtPA as selected by } \\ & \text { physiologic imaging }\end{aligned}$

ENDOSTROKE NR [287]

START [288] 0-8 h Efficacy of the Penumbra System in AlS with a known core infarct volume at admission presenting within $8 \mathrm{~h}$ of onset. To study the correlation between infarct-volume and functional outcome at 90 days in MT treated patients
Inclusion criteria

Premorbid mRS 0-2

Age $\geq 18$

Suspected LVO AIS identified by a

RACE scale score $>4$ evaluated by EMS professional

Time to arrival at EVT-SC $<7 \mathrm{~h}$ from symptom onset

Age 18-90 years

Baseline NIHSSS is $\geq 6$

Time to endovascular treatment

since symptom onset $=6-16 \mathrm{~h}$

Premorbid mRS 0-2

ICA or MCA-M1 occlusion by MRA

or CTA and target mismatch profile

on CTP or MRI (ischemic core

volume $<70 \mathrm{~mL}$, mismatch ratio

$>/=1.8$, and mismatch volume

$>/=15 \mathrm{~mL}$ )

ASPECT on NCCT $>/=6$

No evidence of tumour, mass effect

with midline shift, ICA or aortic dissection

No occlusions in multiple vascular territories

Subjects with failed IV-tPA or

contraindicated for IV-tPA

Age $\geq 18$

Baseline NIHSS $\geq 10$

Can be randomised within 6-24 h of stroke onset

Pre-stroke $\mathrm{mRS} 0$ or 1

$<1 / 3$ MCA territory involved, as evidenced by $C T$ or MRI Intracranial ICA and/or MCA-M1 occlusion on MRA/CTA

CIM defined on MR-DWI or CTP-rCBF maps:

(a) $0-<21 \mathrm{~cm}^{3}$ core infarct and NIHSS $\geq 10$ (and age $\geq 80$ years old), (b) $0-<31 \mathrm{~cm}^{3}$ core infarct and NIHSS $\geq 10$ (and age $<80$ years old), or (c) $31 \mathrm{~cm}^{3}$ to $<51 \mathrm{~cm}^{3}$ core infarct and NIHSS $\geq 20$ (and age $<80$ years old)

ICH or differential diagnosis on CT/MRI

Age $\geq 18$

$\mathrm{NIHSS} \geq 8$ at the time of neuroimaging

Time to the groin puncture $6-12 \mathrm{~h}$

Large vessel proximal occlusion (distal ICA through MCA M1 bifurcation)

Patients who have had IV-tPA without improvement in symptoms

Pre-stroke morbidity mRS 0-1

Presence of large penumbra

No evidence of SAH or ICH or mass effect with

midline shift

$<1 / 3$ MCA territory involved, as evidenced by baseline

CT or ASPECTS of $>7$

Age $\geq 18$ years

Proximal arterial vessel occlusion

No evidence of venous occlusion

Age 18 to 85 years

$\mathrm{NIHSS} \geq 10$ at admission

Evidence of proximal large vessel occlusion (supra clinoid segment of ICA through the M1 segment

of MCA)

Patients presenting within $8 \mathrm{~h}$, and those within

$3 \mathrm{~h}$ must be ineligible or refractory to IV-rtPA

Core infarct volume assessed by CTP, CTA or DWI

scans within 60 min to arterial puncture.

No history of stroke within 3 months

No evidence of mass effect with midline shift or

$\mathrm{ICH}$ on NCCT

No evidence of arterial stenosis proximal to the

occlusion that could prevent thrombectomy

No evidence of preexisting arterial injury

Life expectancy $<90$ days
Outcome measure

mRS at 90 days (shift analysis)

Mortality at 90 days

Mortality in haemorrhagic stroke patients

Clinical deterioration ( $\geq 4$ points on the NIHSS)

Clinical benefit of direct vs. local transfer

Dramatic early favourable response (NIHSS

improvement $\geq 8$ or NIHSS score of $0-2$ at 24 h)

Distribution of $\mathrm{mRS}$ scores at 90 days

Proportion of patients with $\mathrm{mRS} 0-2$

Infarct growth within $24 \mathrm{~h}$

Reperfusion rates at $24 \mathrm{~h}$

Ischemic lesion growth at $24 \mathrm{~h}$

Weighted mRS at 90 days

Mortality at 90 days

Good functional outcome (mRS 0-2)

Revascularization rate at $24 \mathrm{~h}$ on CTA/MRA

Neurological deterioration defined by as

$\geq 4$-point increase in the NIHSS score from the

baseline score at 5-7 days or at discharge.

90 day $\mathrm{mRS}$

Good functional outcome mRS 0-2 at 90 days

Mortality at 30 and 90 days

$\mathrm{CH}$ with neurological deterioration (NIHSS

worsening $>4$ ) within $24 \mathrm{~h}$

Arterial revascularization measured by $\mathrm{TICl} 2 \mathrm{~b}$ or 3 following MT

mRS at 90 days

Complete recanalization defined by TIMI grade two or 3.

Periprocedural complication rate $(\mathrm{slCH}$ defined by ECASS PH1 and $\mathrm{PH} 2, \mathrm{SAH}$ and thromboembolic events).

Good functional outcome mRS $0-2$ at 90 days Recanalization assessment using TIMI and $\mathrm{mTICl}$ immediately after MT

Periprocedural serious events

Good neurological recovery (NIHSS $\geq 10$ ) at discharge Incidence of sICH and asymptomatic haemorrhage defined by ECASS criteria and patient neurological status within $24 \mathrm{~h}$ of the procedure. 
Table $\mathbf{5}$ List of ongoing and upcoming trials aimed to address the issues concerning the endovascular treatment of acute ischemic stroke (Continued)

\begin{tabular}{|c|c|c|c|c|}
\hline Trial & $\begin{array}{l}\text { Time } \\
\text { window }\end{array}$ & Purpose & Inclusion criteria & Outcome measure \\
\hline EASI [289] & $0-5 \mathrm{~h}$ & $\begin{array}{l}\text { To evaluate the efficacy of IV-rtPA } \\
\text { vs combined (MT plus IV-rtPA) } \\
\text { treatment in AIS }\end{array}$ & $\begin{array}{l}\text { Age } \geq 18 \\
\text { NIHSS } \geq 8 \\
\text { Onset to treatment less than } 5 \text { h or symptom/ } \\
\text { imaging mismatch } \\
\text { Occlusion of MCA (m1 or M2), supraclinoid ICA } \\
\text { or basilar trunk } \\
\text { No evidence of haemorrhagic transformation of } \\
\text { the infarcted territory }\end{array}$ & $\begin{array}{l}\text { Favourable clinical outcome (mRS } 0-2 \text { at } 90 \text { days) } \\
\text { sICH on CT at } 24 \mathrm{~h} \\
\text { Infarct evolution on CT between pre-treatment } \\
\text { and } 24 \text { h using the ASPECT score } \\
\text { Recanalization using TICI scale after thrombectomy } \\
\text { Procedural complication within } 3 \text { months } \\
\text { ICH on NCCT at } 24 \mathrm{~h}\end{array}$ \\
\hline
\end{tabular}

$\begin{array}{lll}\text { BASICS } & 0-6 \mathrm{~h} \quad & \text { Efficacy and safety of IAT plus } \\ {[221,222]} & \text { standard medical therapy vs. } \\ & \text { standard medical alone in } \\ & \text { patients with an acute } \\ & \text { symptomatic basilar artery } \\ & \text { occlusion (BAO) }\end{array}$

\begin{tabular}{|c|c|c|}
\hline $\begin{array}{l}\text { SIESTA } \\
{[207,213]}\end{array}$ & NR & $\begin{array}{l}\text { Efficacy of conscious sedatio } \\
\text { vs. general anaesthesia } \\
\text { during IAT. } \\
\text { Update: No advantage for th } \\
\text { use of conscious sedation } \\
\text { recently reported [213]. }\end{array}$ \\
\hline $\begin{array}{l}\text { GOLIATH } \\
{[208]}\end{array}$ & NR & $\begin{array}{l}\text { Efficacy of general vs. local } \\
\text { anaesthesia during IAT }\end{array}$ \\
\hline
\end{tabular}

ANSTROKE NR To study the efficacy of general [209] anaesthesia vs sedation technique during embolectomy for AIS stroke (systolic pressure 140-180 mmHg)

\section{Symptoms of BAO stroke}

BAO confirmed by CTA or MRA

Age $\geq 18$

$\mathrm{NIHSS} \geq 8$ at the time of neuroimaging IAT initiated within $6 \mathrm{~h}$ of onset of symptoms Premorbid score of $0-2$ No ICH or mass effect on CT

\section{Age $\geq 18$ years}

Acute stroke in anterior circulation

ICA or MCA occlusion on CTA

No evidence of $\mathrm{ICH}$

\author{
Age $\geq 18$ years \\ $\mathrm{NIHSS}>10$ \\ $\mathrm{mRS}=<2$ \\ groin puncture $<6 \mathrm{~h}$ from stroke onset \\ occlusion of ICA, ICA-T, M1, M2 \\ $\mathrm{GCS}>9$ \\ No evidence of posterior circulation stroke
}

Age $\geq 18$ years

CTA confirmed occlusion in ICA, ACA (A1 segment), MCA (M1 or M2 segments)

$\mathrm{NIHSS} \geq 14$ for patients with embolus in left

hemisphere or NIHSS $\geq 10$ for embolus in right

hemisphere

No evidence of posterior circulation embolus

No evidence of $\mathrm{ICH}$ on $\mathrm{CT}$

Pre-stroke mRS of $\leq 3$

No evidence of spontaneous recanalization
Favourable outcome mRS 0-2

Excellent outcome mRS 0-3

Recanalization at $24 \pm 6 \mathrm{~h}$ on CTA

Volume of infarction on NCCT and CTA source

images at $24 \pm 6 \mathrm{~h}$

sICH at $24+6 \mathrm{~h}$ on CTA

Mortality at 90 days

NIHSS pre, and port IV-tPA and at $24 \mathrm{~h}$

EQ-5D - Quality of life at 90 and 120 days

Higher NIHSS of $>10$ at $24 \mathrm{~h}$

NIHSS improvement

mRS at 90 days

Mortality before discharge or at 90 days

Duration of hospital stay

Recanalization status on $\mathrm{TICl}$

Periinterventional complications

Growth of DWI lesion (48-72 h]

mRS score at 90 days

Blood pressure during intervention (1-2 h)

Time from arrival to the groin puncture and

recanalization ( $1-2 \mathrm{~h})$

\section{0 day $\mathrm{mRS}$}

Change in NIHSS score compared to admission (Day 3,7 and 90)

Degree of recanalization and reperfusion (1 day after embolectomy)

Periprocedural complications

Infarction magnitude

$C T$ day 1 including CTP

MR on day 3 (2-4) and 3 months

Brain markers (GFAP, Tau, S-100B) before, 2, 24, 48, $72 \mathrm{~h}$ and 3 months after the embolectomy

Quantitative EEG 1, 2 and 90 days after onset Length of hospital stay

Preprocedural time consumption (stroke onset to CTA, CTA to start of anaesthesia/ sedation, stroke onset to start of embolectomy and duration of embolectomy.

$\mathrm{mRS}$ at 90 days

longitudinal model relating 30 day mRS to 90 days $\mathrm{mRS}$

\footnotetext{
MOST [226] NR Phase III trial to explore the efficacy NIHSS $>6$ of IV delivery of antithrombotic medications Argatroban and Eptifibatide in combination with rtPA
} in AIS.

\begin{abstract}
RACECAT Direct Transfer to an Endovascular Centre Compared to Transfer to the Closest Stroke Centre in Acute Stroke Patients With Suspected Large Vessel Occlusion; RACE scale Rapid Arterial occlusion Evaluation; mRS Modified Rankin score; EMS Emergency medical service; LVO Large vessel occlusion; AIS Acute ischemic stroke; LSC Local stroke centre; EVT-LSC Endovascular stroke centre; DEFUSE-3 Endovascular Therapy Following Imaging Evaluation for Ischemic Stroke 3; $D A W N$ Trevo and Medical Management Versus Medical Management Alone in Wake Up and Late Presenting Strokes; BASICS Basilar Artery International Cooperation Study; IAT Intra-arterial therapy; IV-rtPA Intra venous tissue plasminogen activator; NCCT Non-contrast computed tomography; CTA CT angiography; sICH Symptomatic intracranial haemorrhage; SAH Sub-arachnoid haemorrhage; BAO Basilar artery occlusion; SIESTA Sedation vs. Intubation for Endovascular Stroke Treatment; GOLIATH The General or Local Anaesthesia in Intra-arterial Therapy; MOST The Multi-Arm Optimization of Stroke Thrombolysis; NR Not required; ANSTROKE Sedation Versus General Anaesthesia for Endovascular Therapy in Acute Stroke - Impact on Neurological Outcome; ENDOSTROKE International Multicenter Registry for Mechanical Recanalization Procedures in Acute Stroke; TIMI Thrombolysis in Myocardial Infarction; START Imaging Guided Patient Selection for Interventional Revascularization Therapy; EASI Endovascular Acute Stroke Intervention Trial
\end{abstract}

recommend a lower threshold of NIHSS $\geq 7$ on the addition of advanced neuroimaging parameters including ASPECTS $\geq 6$ or 7 , and angiographically confirmed large vessel occlusion with moderate-to-good collaterals on multiphase $\mathrm{CT}$ to select candidates for endovascular MT using stent retriever [230]. With regards to MRI led patient selection based on infarct volume, endovascular therapy is also preferred for large artery occluded AIS patients with small infarct defined by early DWI volume $<70 \mathrm{~mL}$, and an 


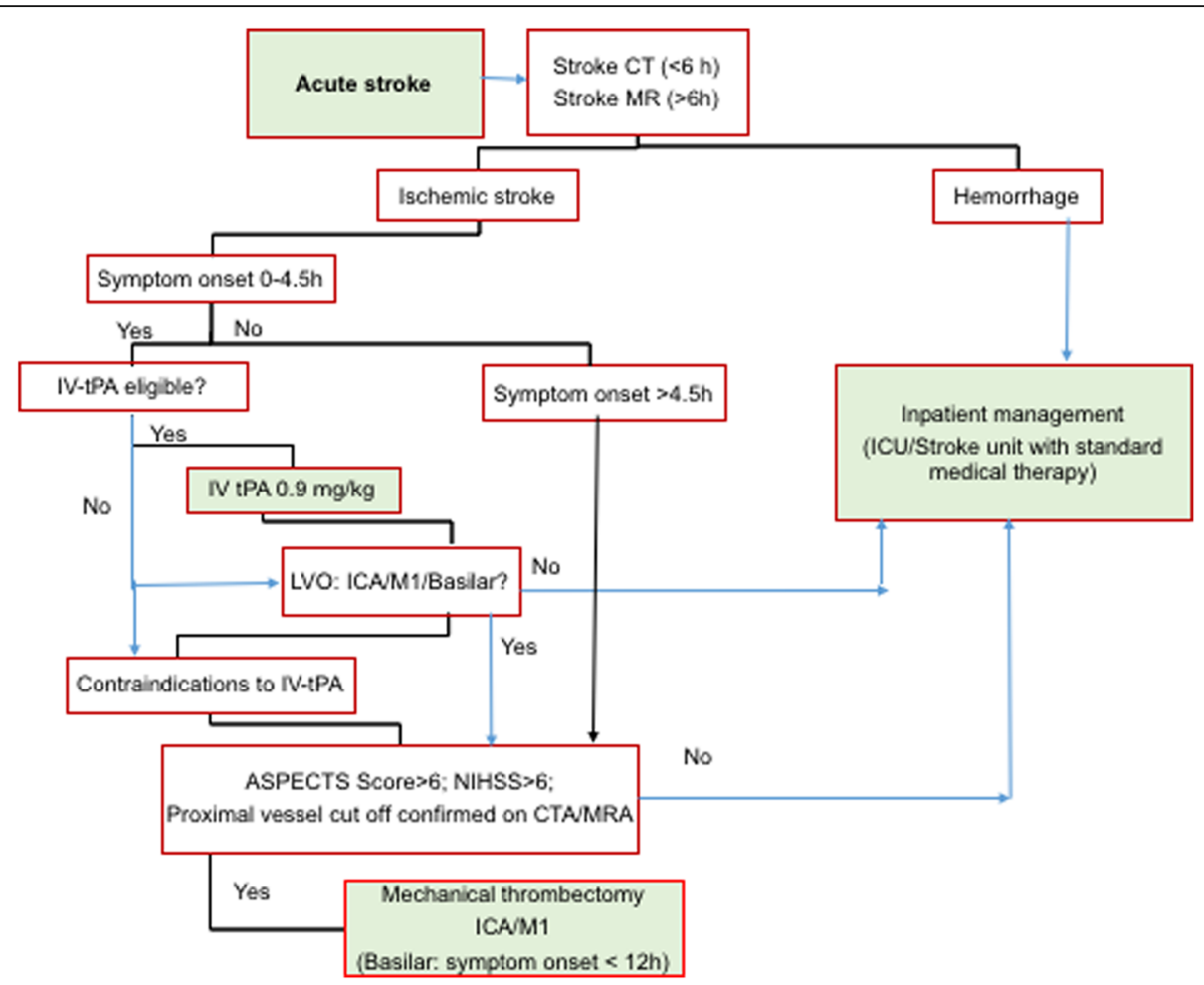

Fig. 2 Workflow diagram detailing the algorithm to select AIS patients with or without large artery occlusion for IV-tPA, MT, or IV-tPA followed by MT. CT = computed tomography; MRI = magnetic resonance imaging; IV-tPA = intravenous trans-plasminogen activator; ICU = intensive care unit; $C T A=C T$ angiography; MRA = MR angiography; $L V O=$ large vessel occlusion; NIHSS = National Institutes of Health Stroke Scale; ICA = internal carotid artery

accessible proximal occlusion. Endovascular MMRT or standalone MT is not suitable with distal occlusion or lacunar stroke. High revascularization yields obtained using (a) MMRT or combinational approaches that include IA/IV thrombolytic agents, stenting, angioplasty, aspiration, clot retrieval, (b) second generation MT devices such as Solitaire and Trevo, (c) combined MT interventions using suction embolectomy with large bore microcatheters such as Penumbra MAX [104-107] and stent retrievers, and (d) with latest generation Penumbra 3D separator [100, 108, 109] are encouraging.

In conclusion, both IV thrombolysis and endovascular treatment have been incorporated into the standard of care in stroke therapy. In light of recent studies in favour of imaging based selection of AIS patients for reperfusion therapy, the time window of MT may extend to $24 \mathrm{~h}$ (or beyond) since symptom onset $[119,202]$. However, further research, exploring bridge therapy or MMRT in addition to advanced imaging-based approaches to select appropriate patients, may also widen the time-window for patient selection and would contribute immensely to early thrombolytic strategies, better recanalization rates, and improved clinical outcomes.

\section{Abbreviations}

AHA/ASA: American Heart Association/American Stroke Association; AIS: Acute Ischemic Stroke; ANSTROKE: Sedation Versus General Anaesthesia for Endovascular Therapy in Acute Stroke; ASPECTS: Alberta Stroke Program Early CT Score; ATLANTIS: Alteplase Thrombolysis for Acute Noninterventional Therapy in Ischemic Stroke; BAO: Basilar artery occlusion; BASICS: Basilar Artery International Cooperation Study; CASES: Canadian Alteplase for Stroke Effectiveness Study; CBV: Cerebral blood volume; CTA: CT angiography; CTP: CT Perfusion; DAWN: DWI or CTP Assessment with Clinical Mismatch in the Triage of Wake-Up and Late Presenting Strokes Undergoing Neurointervention; DEFUSE: Diffusion and Perfusion Imaging Evaluation for Understanding Stroke Evolution; DVT: deep venous thrombosis;

ECASS: European Collaborative Acute Stroke Study; EMS: Emergency medical services; EPITHET: Echoplanar Imaging Thrombolysis Evaluation Trial;

ESCAPE: Endovascular Treatment for Small Core and Anterior Circulation Proximal Occlusion with Emphasis on Minimizing $C T$ to Recanalization Times; ESCAPE: Endovascular Treatment for Small Core and Proximal Occlusion Ischemic Stroke; ESO: European Stroke Organisation; EXTEND-IA: Extending the Time for Thrombolysis in Emergency Neurological Deficits-Intra-arterial: FDA: Federal Drugs Agency; GA: General anaesthesia; GOLIATH: General or Local Anaesthesia in Intra-arterial Therapy; HERMES: Highly Effective Reperfusion evaluated in Multiple Endovascular Stroke Trials; IAT: Intra-arterial thrombolysis; ICA: Internal carotid artery occlusion; ICH: Intra-cerebral hemorrhage; IMS: Interventional Management of Stroke; IST: International Stroke Thrombolysis; IV rtPA: Intravenous recombinant tissue plasminogen activator; MCA: Middle cerebral artery; MELT: Middle Cerebral Artery Embolism Local Fibrinolytic Intervention Trial; MMRT: Multimodal reperfusion therapy; MR CLEAN: Multicenter Randomized Clinical Trial of Endovascular Treatment for Acute Ischemic Stroke in the Netherlands; MRA: Magnetic resonance angiography; mRS: Modified Rankin Score; MT: Mechanical thrombectomy; NCCT: non-contrast computed tomography; NIHSS: National Institutes of Health Stroke Scale; NINDS: National Institute of Neurological Disorders and Stroke; NNT: Number need to treat; PAl: Plasminogen activator 
inhibitor; POSITIVE: Perfusion Imaging Selection of Ischemic Stroke Patients for Endovascular Therapy; PROACT: Prolyse in Acute Cerebral

Thromboembolism; RACE: Rapid artery occlusion evaluation; RACECAT: Direct Transfer to an Endovascular Centre Compared to Transfer to the Closest Stroke Centre in Acute Stroke Patients with Suspected Large Vessel Occlusion; REVASCAT: Randomized Trial of Revascularization with Solitaire FR Device vs Best Medical Therapy in the Treatment of Acute Stroke Due to Anterior Circulation Large Vessel Occlusion Presenting within $8 \mathrm{~h}$ of Symptom Onset; SARIS: Stent-Assisted Recanalization in Acute Ischemic Stroke; SES: Self-expanding stents; sICH: Symptomatic intracerebral haemorrhage; SIESTA: Sedation vs Intubation for Endovascular Stroke Treatment; SITS-ISTR: Safe Implementation of Thrombolysis in StrokeInternational Stroke Thrombolysis Register; SK: Streptokinase; START: ImagingGuided Patient Selection for Interventional Revascularization Therapy; SWIFT PRIME: Solitaire with the Intention for Thrombectomy as Primary Endovascular Treatment of Acute Ischemic Stroke; SYNTHESIS: Local Versus Systemic Thrombolysis for Acute Ischemic Stroke; TAFI: Thrombin-activatable fibrinolysis inhibitor; THERAPY: Assess the Penumbra System in the Treatment of Acute Stroke; THRACE: Trial and Cost-Effectiveness Evaluation of Intraarterial Thrombectomy in Acute Ischemic Stroke; TICl: Thrombolysis in Cerebral Infarction; TIMI: Thrombolysis in Myocardial Infarction; TK: Tenecteplase; TTP: Time to peak; UK: Urokinase; uPA: urinary-type plasminogen activator

\section{Acknowledgements}

We would like to acknowledge Prof Mark Parsons for his critical feedback.

\section{Funding}

Hunter Medical Research Institute, National Health \& Medical Research Council, \& the University of Newcastle.

\section{Availability of data and materials}

Not applicable

\section{Authors' contributions}

$\mathrm{SB}$ and $\mathrm{CL}$ conceptualised the original draft. PS, JRA and DC contributed to the revision of the manuscript. All authors read and approved the final manuscript.

Ethics approval and consent to participate

Not applicable

\section{Consent for publication}

Not applicable

\section{Competing interests}

The authors declare that they have no competing interests.

\section{Publisher's Note}

Springer Nature remains neutral with regard to jurisdictional claims in published maps and institutional affiliations.

\section{Author details}

${ }^{1}$ Western Sydney University (WSU), School of Medicine, South West Sydney Clinical School, Sydney, NSW 2170, Australia. 'Liverpool Hospital, Department of Neurology \& Neurophysiology, Liverpool 2170, NSW, Australia. ${ }^{3}$ The Sydney Partnership for Health, Education, Research \& Enterprise (SPHERE), Liverpool, NSW, Australia. ${ }^{4}$ Stroke \& Neurology Research Group, Ingham Institute for Applied Medical Research, 1 Campbell Street, Liverpool, NSW 2170, Australia. ${ }^{5}$ School of Medicine, University of New South Wales (UNSW), Sydney, NSW, Australia. 'Department of Neurology, John Hunter Hospital, Newcastle, NSW, Australia. ${ }^{7}$ Priority Research Centre for Stroke \& Brain Injury, Faculty of Health \& Medicine, Hunter Medical Research institute (HMRI) and School of Medicine \& Public Health, University of Newcastle, Newcastle, NSW, Australia. ${ }^{8}$ Centre for Clinical Epidemiology \& Biostatistics, Hunter Medical Research Institute, University of Newcastle, Newcastle, NSW, Australia.
Received: 4 October 2017 Accepted: 14 December 2017

Published online: 16 January 2018

\section{References}

1. von Kummer R, Allen KL, Holle R, Bozzao L, Bastianello S, Manelfe C, Bluhmki E, Ringleb P, Meier DH, Hacke W. Acute stroke: usefulness of early CT findings before thrombolytic therapy. Radiology. 1997;205(2):327-33.

2. Hacke W, Donnan G, Fieschi C, Kaste M, von Kummer R, Broderick JP, Brott T, Frankel M, Grotta JC, Haley EC Jr, et al. Association of outcome with early stroke treatment: pooled analysis of ATLANTIS, ECASS, and NINDS rt-PA stroke trials. Lancet. 2004;363(9411):768-74.

3. Lees KR, Bluhmki E, von Kummer R, Brott TG, Toni D, Grotta JC, Albers GW, Kaste M, Marler JR, Hamilton SA, et al. Time to treatment with intravenous alteplase and outcome in stroke: an updated pooled analysis of ECASS, ATLANTIS, NINDS, and EPITHET trials. Lancet. 2010;375(9727):1695-703.

4. NINDS-rtPA: Tissue plasminogen activator for acute ischemic stroke. The National Institute of Neurological Disorders and Stroke rt-PA stroke study group. N Engl J Med. 1995;333(24):1581-7.

5. Kwiatkowski TG, Libman RB, Frankel M, Tilley BC, Morgenstern LB, Lu M, Broderick JP, Lewandowski CA, Marler JR, Levine SR, et al. Effects of tissue plasminogen activator for acute ischemic stroke at one year. National Institute of Neurological Disorders and Stroke recombinant tissue Plasminogen activator stroke study group. N Engl J Med. 1999;340(23):1781-7.

6. Balami JS, Hadley G, Sutherland BA, Karbalai H, Buchan AM. The exact science of stroke thrombolysis and the quiet art of patient selection. Brain. 2013;136(Pt 12):3528-53.

7. Yoo AJ, Pulli B, Gonzalez RG. Imaging-based treatment selection for intravenous and intra-arterial stroke therapies: a comprehensive review. Expert Rev Cardiovasc Ther. 2011;9(7):857-76.

8. Fisher M, Albers GW. Advanced imaging to extend the therapeutic time window of acute ischemic stroke. Ann Neurol. 2013;73(1):4-9.

9. Duffis EJ, Al-Qudah Z, Prestigiacomo CJ, Gandhi C. Advanced neuroimaging in acute ischemic stroke: extending the time window for treatment Neurosurg Focus. 2011;30(6):E5

10. Sandhu GS, Sunshine JL. Advanced neuroimaging to guide acute stroke therapy. Curr Cardiol Rep. 2012;14(6):741-53.

11. Hacke W, Kaste M, Fieschi C, Toni D, Lesaffre E, von Kummer R, Boysen G, Bluhmki E, Hoxter G, Mahagne MH, et al. Intravenous thrombolysis with recombinant tissue plasminogen activator for acute hemispheric stroke. The European cooperative acute stroke study (ECASS). JAMA. 1995;274(13):1017-25.

12. Glauser J. Will EPs' reluctance to embrace Thrombolysis for stroke lead to lawsuits? Emerg Med News. 2006;28(7):23-5.

13. Schmulling S, Grond M, Rudolf J, Heiss WD. One-year follow-up in acute stroke patients treated with rtPA in clinical routine. Stroke. 2000;31(7):1552-4.

14. Emberson J, Lees KR, Lyden P, Blackwell L, Albers G, Bluhmki E, Brott T, Cohen G, Davis S, Donnan G, et al. Effect of treatment delay, age, and stroke severity on the effects of intravenous thrombolysis with alteplase for acute ischaemic stroke: a meta-analysis of individual patient data from randomised trials. Lancet. 2014;384(9958):1929-35.

15. Sandercock P, Wardlaw JM, Lindley RI, Dennis M, Cohen G, Murray G, Innes K, Venables G, Czlonkowska A, Kobayashi A, et al. The benefits and harms of intravenous thrombolysis with recombinant tissue plasminogen activator within $6 \mathrm{~h}$ of acute ischaemic stroke (the third international stroke trial [IST3]): a randomised controlled trial. Lancet. 2012;379(9834):2352-63.

16. Hacke W, Kaste M, Bluhmki E, Brozman M, Davalos A, Guidetti D, Larrue V, Lees KR, Medeghri Z, Machnig T, et al. Thrombolysis with alteplase 3 to 4.5 hours after acute ischemic stroke. N Engl J Med. 2008;359(13):1317-29.

17. Hacke W, Kaste M, Fieschi C, von Kummer R, Davalos A, Meier D, Larrue V, Bluhmki E, Davis S, Donnan G, et al. Randomised double-blind placebocontrolled trial of thrombolytic therapy with intravenous alteplase in acute ischaemic stroke (ECASS II). Second European-Australasian acute stroke study investigators. Lancet. 1998;352(9136):1245-51.

18. Clark WM, Wissman S, Albers GW, Jhamandas JH, Madden KP, Hamilton S. Recombinant tissue-type plasminogen activator (Alteplase) for ischemic stroke 3 to 5 hours after symptom onset. The ATLANTIS study: a randomized controlled trial. Alteplase Thrombolysis for acute noninterventional therapy in ischemic stroke. JAMA. 1999;282(21):2019-26.

19. Clark WM, Albers GW, Madden KP, Hamilton S. The rtPA (alteplase) 0- to 6hour acute stroke trial, part a (A0276g) : results of a double-blind, placebocontrolled, multicenter study. Thromblytic therapy in acute ischemic stroke study investigators. Stroke. 2000;31(4):811-6. 
20. Shobha N, Buchan AM, Hill MD. Thrombolysis at 3-4.5 hours after acute ischemic stroke onset-evidence from the Canadian Alteplase for stroke effectiveness study (CASES) registry. Cerebrovasc Dis. 2011; 31(3):223-8

21. Ahmed N, Wahlgren N, Grond M, Hennerici M, Lees KR, Mikulik R, Parsons M, Roine RO, Toni D, Ringleb P. Implementation and outcome of thrombolysis with alteplase 3-4.5 h after an acute stroke: an updated analysis from SITS-ISTR. Lancet Neurol. 2010;9(9):866-74.

22. Zhang D, Zou X, Sy C, Qin H, Wang Y, Liao X, Liu L. Thrombolysis and reperfusion: advanced understanding of early management strategies in acute ischemic stroke. Neurol Res. 2014;36(5):391-6.

23. Wardlaw JM, Murray V, Berge E, del Zoppo G, Sandercock P, Lindley RL, Cohen $\mathrm{G}$. Recombinant tissue plasminogen activator for acute ischaemic stroke: an updated systematic review and meta-analysis. Lancet. 2012; 379(9834):2364-72.

24. Whiteley WN, Emberson J, Lees KR, Blackwell L, Albers G, Bluhmki E, Brott T, Cohen G, Davis S, Donnan G, et al. Risk of intracerebral haemorrhage with alteplase after acute ischaemic stroke: a secondary analysis of an individual patient data meta-analysis. Lancet Neurol. 2016;15(9):925-33.

25. The European Stroke Organisation (ESO) Executive Committee and the ESO Writing Committee. Guidelines for management of ischaemic stroke and transient ischaemic attack 2008. Cerebrovasc Dis. 2008;25(5):457-507.

26. Del Zoppo GJ, Saver JL, Jauch EC, Adams HP Jr. Expansion of the time window for treatment of acute ischemic stroke with intravenous tissue plasminogen activator: a science advisory from the American Heart Association/American Stroke Association. Stroke. 2009:40(8):2945-8.

27. Khandelwal P, Yavagal DR, Sacco RL. Acute ischemic stroke intervention. J Am Coll Cardiol. 2016;67(22):2631-44.

28. Albers GW, Olivot JM. Intravenous alteplase for ischaemic stroke. Lancet. 2007;369(9558):249-50

29. Medlin F, Amiguet M, Vanacker P, Michel P. Influence of arterial occlusion on outcome after intravenous thrombolysis for acute ischemic stroke. Stroke. 2015;46(1):126-31.

30. Hong JH, Kang J, Jang MU, Kim BJ, Han MK, Park TH, Park SS, Lee KB, Lee $\mathrm{BC}, \mathrm{Yu} \mathrm{KH}$, et al. Recanalization therapy for internal carotid artery occlusion presenting as acute ischemic stroke. J Stroke Cerebrovasc Dis. 2014;23(8): 2183-9.

31. Paciaroni M, Balucani C, Agnelli G, Caso V, Silvestrelli G, Grotta JC, Demchuk AM, Sohn SI, Orlandi G, Leys D, et al. Systemic thrombolysis in patients with acute ischemic stroke and internal carotid ARtery occlusion: the ICARO study. Stroke. 2012;43(1):125-30.

32. Paciaroni M, Agnelli G, Caso V, Pieroni A, Bovi P, Cappellari M, Zini A, Nichelli P, Inzitari D, Nesi M, et al. Intravenous thrombolysis for acute ischemic stroke associated to extracranial internal carotid artery occlusion: the ICARO-2 study. Cerebrovasc Dis. 2012;34(5-6):430-5.

33. Saqqur M, Tsivgoulis G, Molina CA, Demchuk AM, Shuaib A, Alexandrov AV, Investigators C. Residual flow at the site of intracranial occlusion on transcranial Doppler predicts response to intravenous thrombolysis: a multicenter study. Cerebrovasc Dis. 2009;27(1):5-12.

34. Saqqur M, Uchino K, Demchuk AM, Molina CA, Garami Z, Calleja S, Akhtar N, Orouk FO, Salam A, Shuaib A, et al. Site of arterial occlusion identified by transcranial Doppler predicts the response to intravenous thrombolysis for stroke. Stroke. 2007;38(3):948-54.

35. Rubiera M, Ribo M, Delgado-Mederos R, Santamarina E, Delgado P, Montaner J, Alvarez-Sabin J, Molina CA. Tandem internal carotid artery/ middle cerebral artery occlusion: an independent predictor of poor outcome after systemic thrombolysis. Stroke. 2006;37(9):2301-5.

36. Zhu W, Xiao L, Lin M, Liu X, Yan B. Large-vessel occlusion is associated with poor outcome in stroke patients aged 80 years or older who underwent intravenous Thrombolysis. J Stroke Cerebrovasc Dis. 2016;25(11):2712-6.

37. Rai A, Cline B, Williams E, Carpenter J, Roberts T. Intravenous thrombolysis outcomes in patients presenting with large vessel acute ischemic strokesCT angiography-based prognosis. J Neuroimaging. 2015;25(2):238-42.

38. Zhu W, Churilov L, Campbell BC, Lin M, Liu X, Davis SM, Yan B. Does large vessel occlusion affect clinical outcome in stroke with mild neurologic deficits after intravenous thrombolysis? J Stroke Cerebrovasc Dis. 2014; 23(10):2888-93.

39. Linfante I, Llinas RH, Selim M, Chaves C, Kumar S, Parker RA, Caplan LR, Schlaug G. Clinical and vascular outcome in internal carotid artery versus middle cerebral artery occlusions after intravenous tissue plasminogen activator. Stroke. 2002;33(8):2066-71.
40. Lee KY, Han SW, Kim SH, Nam HS, Ahn SW, Kim DJ, Seo SH, Kim DI, Heo JH. Early recanalization after intravenous administration of recombinant tissue plasminogen activator as assessed by pre- and post-thrombolytic angiography in acute ischemic stroke patients. Stroke. 2007;38(1):192-3.

41. von Kummer R, Hacke W. Safety and efficacy of intravenous tissue plasminogen activator and heparin in acute middle cerebral artery stroke. Stroke. 1992;23(5):646-52.

42. Riedel CH, Zimmermann P, Jensen-Kondering U, Stingele R, Deuschl G, Jansen $\mathrm{O}$. The importance of size: successful recanalization by intravenous thrombolysis in acute anterior stroke depends on thrombus length. Stroke. 2011;42(6):1775-7.

43. Friedrich B, Gawlitza M, Schob S, Hobohm C, Raviolo M, Hoffmann KT, Lobsien D. Distance to thrombus in acute middle cerebral artery occlusion: a predictor of outcome after intravenous thrombolysis for acute ischemic stroke. Stroke. 2015:46(3):692-6.

44. Riedel $\mathrm{CH}$, Jensen $\mathrm{U}$, Rohr A, Tietke M, Alfke $\mathrm{K}$, Ulmer S, Jansen O. Assessment of thrombus in acute middle cerebral artery occlusion using thin-slice nonenhanced computed tomography reconstructions. Stroke. 2010;41(8):1659-64.

45. Strbian D, Sairanen T, Silvennoinen H, Salonen O, Lindsberg PJ. Intravenous thrombolysis of basilar artery occlusion: thrombus length versus recanalization success. Stroke. 2014;45(6):1733-8.

46. Liu X. Beyond the time window of intravenous thrombolysis: standing by or by stenting? Interv Neurol. 2012;1(1):3-15.

47. Wolpert SM, Bruckmann H, Greenlee R, Wechsler L, Pessin MS, del Zoppo GJ. Neuroradiologic evaluation of patients with acute stroke treated with recombinant tissue plasminogen activator. The rt-PA acute stroke study group. AJNR Am J Neuroradiol. 1993;14(1):3-13.

48. Lum C, Stys PK, Hogan MJ, Nguyen TB, Srinivasan A, Goyal M. Acute anterior circulation stroke: recanalization using clot angioplasty. Can J Neurol Sci. 2006;33(2):217-22.

49. Albers GW, von Kummer R, Truelsen T, Jensen JK, Ravn GM, Gronning BA, Chabriat H, Chang KC, Davalos AE, Ford GA, et al. Safety and efficacy of desmoteplase given 3-9 h after ischaemic stroke in patients with occlusion or high-grade stenosis in major cerebral arteries (DIAS-3): a double-blind, randomised, placebo-controlled phase 3 trial. Lancet Neurol. 2015;14(6):575-84.

50. Furlan AJ, Eyding D, Albers GW, Al-Rawi Y, Lees KR, Rowley HA, Sachara C, Soehngen M, Warach S, Hacke W. Dose escalation of Desmoteplase for acute ischemic stroke (DEDAS): evidence of safety and efficacy 3 to 9 hours after stroke onset. Stroke. 2006;37(5):1227-31.

51. Hacke W, Albers G, Al-Rawi Y, Bogousslavsky J, Davalos A, Eliasziw M, Fischer M, Furlan A, Kaste M, Lees KR, et al. The Desmoteplase in acute ischemic stroke trial (DIAS): a phase II MRI-based 9-hour window acute stroke thrombolysis trial with intravenous desmoteplase. Stroke. 2005;36(1):66-73

52. Hacke W, Furlan AJ, Al-Rawi Y, Davalos A, Fiebach JB, Gruber F, Kaste M, Lipka LJ, Pedraza S, Ringleb PA, et al. Intravenous desmoteplase in patients with acute ischaemic stroke selected by MRI perfusion-diffusion weighted imaging or perfusion CT (DIAS-2): a prospective, randomised, double-blind, placebo-controlled study. Lancet Neurol. 2009;8(2):141-50.

53. Mori E, Minematsu K, Nakagawara J, Hasegawa Y, Nagahiro S, Okada Y, Truelsen T, Lindsten A, Ogawa A, Yamaguchi T. Safety and tolerability of Desmoteplase within 3 to 9 hours after symptoms onset in Japanese patients with ischemic stroke. Stroke. 2015:46(9):2549-54.

54. Sugg RM, Pary JK, Uchino K, Baraniuk S, Shaltoni HM, Gonzales NR, Mikulik R, Garami Z, Shaw SG, Matherne DE, et al. Argatroban tPA stroke study: study design and results in the first treated cohort. Arch Neurol. 2006;63(8):1057-62.

55. Haley EC Jr, Lyden PD, Johnston KC, Hemmen TM. A pilot dose-escalation safety study of tenecteplase in acute ischemic stroke. Stroke. 2005;36(3): 607-12.

56. Ginsberg MD, Hill MD, Palesch YY, Ryckborst KJ, Tamariz D. The ALIAS pilot trial: a dose-escalation and safety study of albumin therapy for acute ischemic stroke-l: physiological responses and safety results. Stroke. 2006; 37(8):2100-6.

57. Marder VJ, Jahan R, Gruber T, Goyal A, Arora V. Thrombolysis with plasmin: implications for stroke treatment. Stroke. 2010;41(10 Suppl):S45-9.

58. Gurm HS, Lincoff AM, Lee D, Tang WH, Jia G, Booth JE, Califf RM, Ohman EM, Van de Werf F, Armstrong PW, et al. Outcome of acute ST-segment elevation myocardial infarction in diabetics treated with fibrinolytic or combination reduced fibrinolytic therapy and platelet glycoprotein IIb/Illa inhibition: lessons from the GUSTO V trial. J Am Coll Cardiol. 2004;43(4):542-8. 
59. Lincoff AM, Califf RM, Van de Werf F, Willerson JT, White HD, Armstrong PW, Guetta V, Gibler WB, Hochman JS, Bode C, et al. Mortality at 1 year with combination platelet glycoprotein $\mathrm{Ilb} / \mathrm{lll}$ in inhibition and reduced-dose fibrinolytic therapy vs conventional fibrinolytic therapy for acute myocardial infarction: GUSTO V randomized trial. JAMA. 2002;288(17):2130-5.

60. Topol EJ. Reperfusion therapy for acute myocardial infarction with fibrinolytic therapy or combination reduced fibrinolytic therapy and platelet glycoprotein IIb/Illa inhibition: the GUSTO V randomised trial. Lancet. 2001; 357(9272):1905-14.

61. Uyttenboogaart M, Koch MW, Koopman K, Vroomen PC, De Keyser J, Luijckx GJ. Safety of antiplatelet therapy prior to intravenous thrombolysis in acute ischemic stroke. Arch Neurol. 2008;65(5):607-11.

62. Zinkstok SM, Vermeulen M, Stam J, de Haan RJ, Roos YB. Antiplatelet therapy in combination with rt-PA thrombolysis in ischemic stroke (ARTIS): rationale and design of a randomized controlled trial. Cerebrovasc Dis. 2010; 29(1):79-81.

63. Zinkstok SM, Vermeulen M, Stam J, de Haan RJ, Roos YB. A randomised controlled trial of antiplatelet therapy in combination with Rt-PA thrombolysis in ischemic stroke: rationale and design of the ARTIS-trial. Trials. 2010;11:51.

64. Lorenzano S, Toni D. TESPI (Thrombolysis in elderly stroke patients in Italy): a randomized controlled trial of alteplase (rt-PA) versus standard treatment in acute ischaemic stroke in patients aged more than 80 years where thrombolysis is initiated within three hours after stroke onset. Int J Stroke. 2012;7(3):250-7.

65. Mikulik R, Dufek M, Goldemund D, Reif M. A pilot study on systemic thrombolysis followed by low molecular weight heparin in ischemic stroke. Eur J Neurol. 2006;13(10):1106-11.

66. Alexandrov AV, Molina CA, Grotta JC, Garami Z, Ford SR, Alvarez-Sabin J, Montaner J, Saqqur M, Demchuk AM, Moye LA, et al. Ultrasound-enhanced systemic thrombolysis for acute ischemic stroke. N Engl J Med. 2004;351(21): 2170-8

67. Alexandrov AV, Wojner AW, Grotta JC. CLOTBUST: design of a randomized trial of ultrasound-enhanced thrombolysis for acute ischemic stroke. Neuroimaging. 2004;14(2):108-12.

68. Eggers J, Konig IR, Koch B, Handler G, Seidel G. Sonothrombolysis with transcranial color-coded sonography and recombinant tissue-type plasminogen activator in acute middle cerebral artery main stem occlusion: results from a randomized study. Stroke. 2008;39(5):1470-5.

69. Saqqur M, Shuaib A, Alexandrov AV, Sebastian J, Khan K, Uchino K. The correlation between admission blood glucose and intravenous rt-PAinduced arterial recanalization in acute ischemic stroke: a multi-Centre TCD study. Int J Stroke. 2015;10(7):1087-92.

70. Tsivgoulis G, Zhang Y, Alexandrov AW, Harrigan MR, Sisson A, Zhao L, Brethour M, Cava L, Balucani C, Barlinn K, et al. Safety and tolerability of early noninvasive ventilatory correction using bilevel positive airway pressure in acute ischemic stroke. Stroke. 2011;42(4):1030-4

71. Toda N, Tanaka T, Ayajiki K, Okamura T. Cerebral vasodilatation induced by stimulation of the pterygopalatine ganglion and greater petrosal nerve in anesthetized monkeys. Neuroscience. 2000;96(2):393-8.

72. Barreto $A D$, Alexandrov AV. Adjunctive and alternative approaches to current reperfusion therapy. Stroke. 2012;43(2):591-8.

73. Martin PJ, Enevoldson TP, Humphrey PR. Causes of ischaemic stroke in the young. Postgrad Med J. 1997;73(855):8-16.

74. Gobin YP, Starkman S, Duckwiler GR, Grobelny T, Kidwell CS, Jahan R, PileSpellman J, Segal A, Vinuela F, Saver JL. MERCI 1: a phase 1 study of mechanical embolus removal in cerebral ischemia. Stroke. 2004:35(12):2848-54

75. Meyers PM, Schumacher HC, Connolly ES Jr, Heyer EJ, Gray WA, Higashida RT. Current status of endovascular stroke treatment. Circulation. 2011. 123(22):2591-601.

76. Campbell BC, Mitchell PJ, Kleinig TJ, Dewey HM, Churilov L, Yassi N, Yan B, Dowling RJ, Parsons MW, Oxley TJ, et al. Endovascular therapy for ischemic stroke with perfusion-imaging selection. N Engl J Med. 2015;372(11):1009-18.

77. Novakovic R, Toth G, Purdy PD. Review of current and emerging therapies in acute ischemic stroke. J Neurointerv Surg. 2009;1(1):13-26.

78. Smith WS, Sung G, Starkman S, Saver JL, Kidwell CS, Gobin YP, Lutsep HL, Nesbit GM, Grobelny T, Rymer MM, et al. Safety and efficacy of mechanical embolectomy in acute ischemic stroke: results of the MERCI trial. Stroke. 2005;36(7):1432-8.

79. Smith WS. Safety of mechanical thrombectomy and intravenous tissue plasminogen activator in acute ischemic stroke. Results of the multi mechanical embolus removal in cerebral ischemia (MERCI) trial, part I. AJNR Am J Neuroradiol. 2006;27(6):1177-82

80. Asadi H, Dowling R, Yan B, Wong S, Mitchell P. Advances in endovascular treatment of acute ischaemic stroke. Intern Med J. 2015;45(8):798-805.

81. del Zoppo GJ, Higashida RT, Furlan AJ, Pessin MS, Rowley HA, Gent M. PROACT: a phase II randomized trial of recombinant pro-urokinase by direct arterial delivery in acute middle cerebral artery stroke. PROACT investigators. Prolyse in acute cerebral Thromboembolism. Stroke. 1998;29(1):4-11.

82. Furlan A, Higashida R, Wechsler L, Gent M, Rowley H, Kase C, Pessin M, Ahuja A, Callahan F, Clark WM, et al. Intra-arterial prourokinase for acute ischemic stroke. The PROACT II study: a randomized controlled trial. Prolyse in acute cerebral Thromboembolism. JAMA. 1999;282(21):2003-11.

83. Ciccone A, Valvassori L, Nichelatti M, Sgoifo A, Ponzio M, Sterzi R, Boccardi E. Endovascular treatment for acute ischemic stroke. N Engl J Med. 2013; 368(10):904-13.

84. Ogawa A, Mori E, Minematsu K, Taki W, Takahashi A, Nemoto S, Miyamoto S, Sasaki $M$, Inoue T. Randomized trial of Intraarterial infusion of Urokinase within 6 hours of middle cerebral artery stroke. Stroke. 2007;38(10):2633.

85. Lee M, Hong KS, Saver JL. Efficacy of intra-arterial fibrinolysis for acute ischemic stroke: meta-analysis of randomized controlled trials. Stroke. 2010; 41(5):932-7.

86. Adams H, Adams R, Del Zoppo G, Goldstein LB. Guidelines for the early management of patients with ischemic stroke: 2005 guidelines update a scientific statement from the stroke Council of the American Heart Association/American Stroke Association. Stroke. 2005;36(4):916-23.

87. Fanous AA, Siddiqui AH. Mechanical thrombectomy: stent retrievers vs. aspiration catheters. Cor et Vasa. 2016;58(2):e193-203.

88. The Penumbra Pivotal Stroke Trial Investigators. The penumbra pivotal stroke trial: safety and effectiveness of a new generation of mechanical devices for clot removal in intracranial large vessel occlusive disease. Stroke. 2009;40(8):2761-8.

89. Bose A, Henkes H, Alfke K, Reith W, Mayer TE, Berlis A, Branca V, Sit SP. The penumbra system: a mechanical device for the treatment of acute stroke due to thromboembolism. AJNR Am J Neuroradiol. 2008;29(7):1409-13.

90. Pereira VM, Yilmaz H, Pellaton A, Slater LA, Krings T, Lovblad KO. Current status of mechanical thrombectomy for acute stroke treatment. J Neuroradiol. 2015;42(1):12-20.

91. Almekhlafi MA, Menon BK, Freiheit EA, Demchuk AM, Goyal M. A metaanalysis of observational intra-arterial stroke therapy studies using the merci device, penumbra system, and retrievable stents. AJNR Am J Neuroradiol. 2013;34(1):140-5.

92. Gupta R, Xiang B, Ge S, Sun CH, Yoo AJ, Mehta BP. Stagnation of treatment times over a decade: results of a pooled analysis from the $\mathrm{MERCI}$ registry, MERCI, TREVO, and TREVO 2 trials. J Neurointerv Surg. 2016:8(5):453-6.

93. Nogueira RG, Lutsep HL, Gupta R, Jovin TG, Albers GW, Walker GA, Liebeskind DS, Smith WS. Trevo versus merci retrievers for thrombectomy revascularisation of large vessel occlusions in acute ischaemic stroke (TREVO 2): a randomised trial. Lancet. 2012;380(9849):1231-40.

94. Saver JL, Jahan R, Levy El, Jovin TG, Baxter B, Nogueira R, Clark W, Budzik R, Zaidat OO. SOLITAIRE with the intention for thrombectomy (SWIFT) trial: design of a randomized, controlled, multicenter study comparing the SOLITAIRE flow restoration device and the $\mathrm{MERCI}$ retriever in acute ischaemic stroke. Int J Stroke. 2014;9(5):658-68.

95. Mordasini P, Hiller M, Brekenfeld C, Schroth G, Fischer U, Slotboom J, Arnold $M$, Gralla J. In vivo evaluation of the Phenox CRC mechanical thrombectomy device in a swine model of acute vessel occlusion. AJNR Am J Neuroradiol. 2010;31(5):972-8.

96. Prothmann S, Lockau H, Dorn F, Poppert H, Forschler A, Zimmer C, Liebig T: The phenox clot retriever as part of a multimodal mechanical thrombectomy approach in acute ischemic stroke: single center experience in 56 patients. TheScientificWorldJOURNAL 2012, 2012:190763.

97. Brekenfeld C, Schroth G, El-Koussy M, Nedeltchev K, Reinert M, Slotboom J, Gralla J. Mechanical thromboembolectomy for acute ischemic stroke: comparison of the catch thrombectomy device and the merci retriever in vivo. Stroke. 2008;39(4):1213-9.

98. Mourand I, Brunel H, Costalat V, Riquelme C, Lobotesis K, Milhaud D, Heroum C, Arquizan C, Moynier M, Bonafe A. Mechanical thrombectomy in acute ischemic stroke: catch device. AJNR Am J Neuroradiol. 2011;32(8):1381-5.

99. Peker A, Arsava EM, Topcuoglu MA, Arat A. Catch plus thrombectomy device in acute stroke: initial evaluation. J Neurointerv Surg. 2016;9(12): 1214-18. 
100. Przybylowski CJ, Ding D, Starke RM, Durst CR, Crowley RW, Liu KC. Evolution of endovascular mechanical thrombectomy for acute ischemic stroke. World J Clin Cases. 2014;2(11):614-22.

101. Raychev R, Saver JL. Mechanical thrombectomy devices for treatment of stroke. Neurol Clin Pract. 2012;2(3):231-5.

102. Fargen KM, Meyers PM, Khatri P, Mocco J. Improvements in recanalization with modern stroke therapy: a review of prospective ischemic stroke trials during the last two decades. J Neurointerv Surg. 2013;5(6):506-11.

103. Hu YC, Stiefel MF. Force and aspiration analysis of the ADAPT technique in acute ischemic stroke treatment. J Neurointerv Surg. 2016;8(3):244-6.

104. John S, Hussain MS, Toth G, Bain M, Uchino K, Hui FK. Initial experience using the 5MAX ACE reperfusion catheter in intra-arterial therapy for acute ischemic stroke. J Cerebrovasc Endovasc Neurosurg. 2014;16(4):350-7.

105. Navia P, Larrea JA, Pardo E, Arce A, Martinez-Zabaleta M, Diez-Gonzalez N, Murias E, Arraez-Aybar LA, Masso J. Initial experience using the 3 MAX cerebral reperfusion catheter in the endovascular treatment of acute ischemic stroke of distal arteries. J Neurointerv Surg. 2016;8(8):787-90,

106. Suzuki K, Aoki J, Sakamoto Y, Kanamaru T, Abe A, Suda S, Okubo S, Kimura K. Efficiency of the penumbra 5MAX ACE reperfusion catheter in acute ischemic stroke patients. J Stroke Cerebrovasc Dis. 2016;25(12):2981-6.

107. Vidal GA, Milburn JM. The penumbra 5MAX ACE catheter is safe, efficient, and cost saving as a primary mechanical Thrombectomy device for large vessel occlusions in acute ischemic stroke. Ochsner J. 2016;16(4):486-91.

108. Mpotsaris A, Bussmeyer M, Weber W. Mechanical thrombectomy with the penumbra 3D separator and lesional aspiration: technical feasibility and clinical outcome. Clin Neuroradiol. 2014;24(3):245-50.

109. Behme D, Kowoll A, Mpotsaris A, Hader C, Hechelhammer L, Weber J, Weber W. Multicenter clinical experience in over 125 patients with the penumbra separator 3D for mechanical thrombectomy in acute ischemic stroke. J Neurointerv Surg. 2016;8(1):8-12.

110. Berkhemer OA, Fransen PS, Beumer D, van den Berg LA, Lingsma HF, Yoo AJ, Schonewille WJ, Vos JA, Nederkoorn PJ, Wermer MJ, et al. A randomized trial of intraarterial treatment for acute ischemic stroke. N Engl J Med. 2015; 372(1):11-20.

111. Goyal M, Demchuk AM, Menon BK, Eesa M, Rempel JL, Thornton J, Roy D, Jovin TG, Willinsky RA, Sapkota BL, et al. Randomized assessment of rapid endovascular treatment of ischemic stroke. N Engl J Med. 2015;372(11): 1019-30.

112. Saver JL, Goyal M, Bonafe A, Diener HC, Levy El, Pereira VM, Albers GW, Cognard C, Cohen DJ, Hacke W, et al. Stent-retriever thrombectomy after intravenous t-PA vs. t-PA alone in stroke. N Engl J Med. 2015;372(24):2285-95.

113. Jovin TG, Chamorro A, Cobo E, de Miquel MA, Molina CA, Rovira A, San Roman L, Serena J, Abilleira S, Ribo M, et al. Thrombectomy within 8 hours after symptom onset in ischemic stroke. N Engl J Med. 2015;372(24):2296-306.

114. Berkhemer OA, Majoie CB, Dippel DW. Endovascular therapy for ischemic stroke. N Engl J Med. 2015;372(24):2363.

115. Goyal M, Yu AY, Menon BK, Dippel DW, Hacke W, Davis SM, Fisher M, Yavagal DR, Turjman F, Ross J, et al. Endovascular therapy in acute ischemic stroke: challenges and transition from trials to bedside. Stroke. 2016;47(2): 548-53

116. Albers GW, Goyal M, Jahan R, Bonafe A, Diener HC, Levy El, Pereira VM, Cognard C, Cohen DJ, Hacke W, et al. Ischemic core and hypoperfusion volumes predict infarct size in SWIFT PRIME. Ann Neurol. 2016;79(1):76-89.

117. Goyal M, Menon BK, van Zwam WH, Dippel DW, Mitchell PJ, Demchuk AM, Davalos A, Majoie CB, van der Lugt A, de Miquel MA, et al. Endovascular thrombectomy after large-vessel ischaemic stroke: a meta-analysis of individual patient data from five randomised trials. Lancet. 2016;387(10029): 1723-31.

118. Saver JL, Goyal M, van der Lugt A, et al. Time to treatment with endovascular thrombectomy and outcomes from ischemic stroke: a metaanalysis. JAMA. 2016;316(12):1279-89.

119. Nogueira RG, Jadhav AP, Haussen DC, Bonafe A, Budzik RF, Bhuva P, Yavagal DR, Ribo M, Cognard C, Hanel RA et al. Thrombectomy 6 to 24 hours after stroke with a mismatch between deficit and infarct. N Engl J Med. 2018; 378(1):11-21.

120. Kidwell CS, Jahan R, Gornbein J, Alger JR, Nenov V, Ajani Z, Feng L, Meyer BC, Olson S, Schwamm LH, et al. A trial of imaging selection and endovascular treatment for ischemic stroke. N Engl J Med. 2013;368(10):914-23.

121. Broderick JP, Palesch YY, Demchuk AM, Yeatts SD, Khatri P, Hill MD, Jauch EC, Jovin TG, Yan B, Silver FL, et al. Endovascular therapy after intravenous tPA versus t-PA alone for stroke. N Engl J Med. 2013;368(10):893-903.
122. Mokin M, Khalessi AA, Mocco J, Lanzino G, Dumont TM, Hanel RA, Lopes DK, Fessler RD 2nd, Ringer AJ, Bendok BR, et al. Endovascular treatment of acute ischemic stroke: the end or just the beginning? Neurosurg Focus. 2014;36(1):E5.

123. Mocco J, O'Kelly C, Arthur A, Meyers PM, Hirsch JA, Woo HH, Rasmussen PA, Albuquerque FC, Turk A, Tarr R, et al. Randomized clinical trials: the double edged sword. J Neurointerv Surg. 2013;5(5):387-90.

124. Goyal M, Shamy M, Menon BK, Saver JL, Diener HC, Mocco J, Pereira VM, Jovin TG, Zaidat O, Levy El, et al. Endovascular stroke trials: why we must enroll all eligible patients. Stroke. 2013;44(12):3591-5.

125. Campbell BC, Hill MD, Rubiera M, Menon BK, Demchuk A, Donnan GA, Roy D, Thornton J, Dorado L, Bonafe A, et al. Safety and efficacy of solitaire stent Thrombectomy: individual patient data meta-analysis of randomized trials. Stroke. 2016;47(3):798-806.

126. Saver JL, Jahan R, Levy El, Jovin TG, Baxter B, Nogueira RG, Clark W, Budzik R, Zaidat $\mathrm{OO}$. Solitaire flow restoration device versus the merci retriever in patients with acute ischaemic stroke (SWIFT): a randomised, parallel-group, non-inferiority trial. Lancet. 2012;380(9849):1241-9.

127. Bracard S, Ducrocq X, Mas JL, Soudant M, Oppenheim C, Moulin T. Guillemin F, investigators T: mechanical thrombectomy after intravenous alteplase versus alteplase alone after stroke (THRACE): a randomised controlled trial. Lancet Neurol. 2016;15(11):1138-47.

128. Mocco J, Kuo S, Khatri P, Zaidat OO. 186 the THERAPY trial: a prospective, randomized, concurrent controlled trial to evaluate the role of mechanical Embolectomy as adjunctive treatment to IV rtPA for acute ischemic stroke. Neurosurgery. 2013;60(Suppl 1);181-2.

129. Smith WS, Sung G, Saver J, Budzik R, Duckwiler G, Liebeskind DS, Lutsep HL, Rymer MM, Higashida RT, Starkman S, et al. Mechanical thrombectomy for acute ischemic stroke: final results of the multi MERCI trial. Stroke. 2008; 39(4):1205-12

130. Berlis A, Lutsep $H$, Barnwell S, Norbash A, Wechsler L, Jungreis CA, Woolfenden A, Redekop G, Hartmann M, Schumacher M. Mechanical thrombolysis in acute ischemic stroke with endovascular photoacoustic recanalization. Stroke. 2004;35(5):1112-6.

131. Meurer WJ, Barth BE, Gaddis G, Vilke GM, Lam SH. Rapid systematic review: intra-arterial Thrombectomy ("clot retrieval") for selected patients with acute ischemic stroke. J Emerg Med. 2017;52(2):255-61.

132. Investigators PPST. The penumbra pivotal stroke trial: safety and effectiveness of a new generation of mechanical devices for clot removal in intracranial large vessel occlusive disease. Stroke. 2009;40(8):2761-8.

133. Alshekhlee A, Pandya DJ, English J, Zaidat OO, Mueller N, Gupta R, Nogueira RG. Merci mechanical thrombectomy retriever for acute ischemic stroke therapy: literature review. Neurology. 2012;79(13 Suppl 1):S126-34.

134. Lee W, Sitoh YY, Lim CC, Lim WE, Hui FK. The MERCI retrieval system for the management of acute ischaemic stroke-the NNI Singapore experience. Ann Acad Med Singap. 2009;38(9):749-55.

135. Nogueira RG, Schwamm LH, Hirsch JA. Endovascular approaches to acute stroke, part 1: drugs, devices, and data. AJNR Am J Neuroradiol. 2009;30(4): 649-61.

136. Yeo LL, Paliwal P, Teoh HL, Seet RC, Chan BP, Wakerley B, Liang S, Rathakrishnan R, Chong VF, Ting EY, et al. Early and continuous neurologic improvements after intravenous thrombolysis are strong predictors of favorable long-term outcomes in acute ischemic stroke. J Stroke Cerebrovasc Dis. 2013;22(8):e590-6.

137. Sekoranja L, Loulidi J, Yilmaz H, Lovblad K, Temperli P, Comelli M, Sztajzel RF. Intravenous versus combined (intravenous and intra-arterial) thrombolysis in acute ischemic stroke: a transcranial color-coded duplex sonography-guided pilot study. Stroke. 2006;37(7):1805-9.

138. Rubiera M, Ribo M, Pagola J, Coscojuela P, Rodriguez-Luna D, Maisterra O, Ibarra B, Pineiro S, Meler P, Romero FJ, et al. Bridging intravenous-intraarterial rescue strategy increases recanalization and the likelihood of a good outcome in nonresponder intravenous tissue plasminogen activator-treated patients: a case-control study. Stroke. 2011;42(4):993-7.

139. Ribo M, Molina CA, Alvarez B, Rubiera M, Alvarez-Sabin J, Matas M. Intraarterial administration of microbubbles and continuous 2-MHz ultrasound insonation to enhance intra-arterial thrombolysis. J Neuroimaging. 2010; 20(3):224-7

140. Lewandowski CA, Frankel M, Tomsick TA, Broderick J, Frey J, Clark W, Starkman S, Grotta J, Spilker J, Khoury J, et al. Combined intravenous and intra-arterial rTPA versus intra-arterial therapy of acute ischemic stroke: emergency Management of Stroke (EMS) bridging trial. Stroke. 1999;30(12):2598-605. 
141. Kass-Hout T, Kass-Hout O, Mokin M, Thesier DM, Yashar P, Orion D, Jahshan S, Hopkins LN, Siddiqui AH, Snyder KV, et al. Is bridging with intravenous thrombolysis of any benefit in endovascular therapy for acute ischemic stroke? World Neurosurg. 2014;82(3-4):e453-8.

142. Wechsler LR, Jovin TG. Intravenous recombinant tissue-type plasminogen activator in the extended time window and the US Food and Drug Administration: confused about the time. Stroke. 2012;43(9):2517-9.

143. IMS Study Investigators. Combined intravenous and intra-arterial recanalization for acute ischemic stroke: the Interventional Management of Stroke Study. Stroke. 2004;35(4):904-11.

144. IMS I| Trial Investigators. The Interventional Management of Stroke (IMS) || Study. Stroke. 2007;38(7):2127-35.

145. Zaidat OO, Lazzaro MA, Gupta R, Yavagal DR, Rasmussen PA, Hirsch JA, Castonguay AC, Tarr RW: Interventional Management of Stroke III trial: establishing the foundation. J Neurointerv Surg 2012, 4(4):235-237.

146. Rha JH, Saver JL. The impact of recanalization on ischemic stroke outcome: a meta-analysis. Stroke. 2007;38(3):967-73.

147. Levy El, Rahman M, Khalessi AA, Beyer PT, Natarajan SK, Hartney ML, Fiorella DJ, Hopkins LN, Siddiqui AH, Mocco J. Midterm clinical and angiographic follow-up for the first Food and Drug Administration-approved prospective, single-arm trial of primary stenting for stroke: SARIS (stent-assisted Recanalization for acute ischemic stroke). Neurosurgery. 2011;69(4):915-20. discussion 920

148. Levy El, Siddiqui AH, Crumlish A, Snyder KV, Hauck EF, Fiorella DJ, Hopkins LN, Mocco J. First Food and Drug Administration-approved prospective trial of primary intracranial stenting for acute stroke: SARIS (stent-assisted recanalization in acute ischemic stroke). Stroke. 2009;40(11):3552-6.

149. Zaidat OO, Suarez Jl, Santillan C, Sunshine JL, Tarr RW, Paras VH, Selman WR, Landis DM. Response to intra-arterial and combined intravenous and intraarterial thrombolytic therapy in patients with distal internal carotid artery occlusion. Stroke. 2002;33(7):1821-6.

150. Nogueira RG, Yoo AJ, Masrur S, Batista LM, Hakimelahi R, Hirsch JA, Schwamm LH. Safety of full-dose intravenous recombinant tissue plasminogen activator followed by multimodal endovascular therapy for acute ischemic stroke. J Neurointerv Surg. 2013;5(4):298-301.

151. Gupta R, Vora NA, Horowitz MB, Tayal AH, Hammer MD, Uchino K, Levy El, Wechsler LR, Jovin TG. Multimodal reperfusion therapy for acute ischemic stroke: factors predicting vessel recanalization. Stroke. 2006;37(4):986-90.

152. Lin DD, Gailloud P, Beauchamp NJ, Aldrich EM, Wityk RJ, Murphy KJ. Combined stent placement and thrombolysis in acute vertebrobasilar ischemic stroke. AJNR Am J Neuroradiol. 2003;24(9):1827-33.

153. Gupta R, Tayal AH, Levy El, Cheng-Ching E, Rai A, Liebeskind DS, Yoo AJ, Hsu DP, Rymer MM, Zaidat OO, et al. Intra-arterial thrombolysis or stent placement during endovascular treatment for acute ischemic stroke leads to the highest recanalization rate: results of a multicenter retrospective study. Neurosurgery. 2011;68(6):1618-22. discussion 1622-1613

154. Ghobrial GM, Chalouhi N, Rivers L, Witte S, Davanzo J, Dalyai R, Gardecki ML, Jabbour P, Gonzalez F, Dumont AS, et al. Multimodal endovascular management of acute ischemic stroke in patients over 75 years old is safe and effective. J Neurointerv Surg. 2013;5(Suppl 1):i33-7.

155. Egashira Y, Yoshimura S, Enomoto Y, Ishiguro M, Yamada K, Tanaka Y, Iwama T. Efficacy and limitations of multimodal endovascular revascularization other than clot retrieval for acute stroke caused by largevessel occlusion. J Stroke Cerebrovasc Dis. 2013;22(6):851-6.

156. Yoon W, Park MS, Cho KH. Low-dose intra-arterial urokinase and aggressive mechanical clot disruption for acute ischemic stroke after failure of intravenous thrombolysis. AJNR Am J Neuroradiol. 2010;31(1):161-4

157. Nogueira RG, Schwamm LH, Buonanno FS, Koroshetz WJ, Yoo AJ, Rabinov JD, Pryor JC, Hirsch JA. Low-pressure balloon angioplasty with adjuvant pharmacological therapy in patients with acute ischemic stroke caused by intracranial arterial occlusions. Neuroradiology. 2008;50(4):331-40.

158. Lin R, Vora N, Zaidi S, Aleu A, Jankowitz B, Thomas A, Gupta R, Horowitz M, Kim S, Reddy $V$, et al. Mechanical approaches combined with intra-arterial pharmacological therapy are associated with higher recanalization rates than either intervention alone in revascularization of acute carotid terminus occlusion. Stroke. 2009;40(6):2092-7.

159. Leker RR, Grigoriadis S, Cohen JE. Endovascular reperfusion therapy for acute ischemic stroke: a meta-analysis. Neurol Res. 2010;32(8):787-91.

160. Cohen JE, Itshayek E, Moskovici S, Gomori JM, Fraifeld S, Eichel R, Leker RR. State-of-the-art reperfusion strategies for acute ischemic stroke. J Clin Neurosci. 2011;18(3):319-23.
161. Bhatia R, Hill MD, Shobha N, Menon B, Bal S, Kochar P, Watson T, Goyal M, Demchuk AM. Low rates of acute recanalization with intravenous recombinant tissue plasminogen activator in ischemic stroke: real-world experience and a call for action. Stroke. 2010;41(10):2254-8.

162. Demchuk AM, Goyal M, Yeatts SD, Carrozzella J, Foster LD, Qazi E, Hill MD, Jovin TG, Ribo M, Yan B, et al. Recanalization and clinical outcome of occlusion sites at baseline $C T$ angiography in the interventional Management of Stroke III trial. Radiology. 2014;273(1):202-10.

163. Koga M, Arihiro S, Miyashita F, Yamamoto H, Yamada N, Nagatsuka K, Minematsu K, Toyoda K. Factors associated with early recanalization failure following intravenous rt-PA therapy for ischemic stroke. Cerebrovasc Dis. 2013;36(4):299-305.

164. Neumann-Haefelin T, du Mesnil de Rochemont R, Fiebach JB, Gass A, Nolte C, Kucinski T, Rother J, Siebler M, Singer OC, Szabo K, et al. Effect of incomplete (spontaneous and postthrombolytic) recanalization after middle cerebral artery occlusion: a magnetic resonance imaging study. Stroke. 2004 35(1):109-14.

165. Wunderlich MT, Goertler M, Postert T, Schmitt E, Seidel G, Gahn G, Samii C, Stolz E. Recanalization after intravenous thrombolysis: does a recanalization time window exist? Neurology. 2007;68(17):1364-8.

166. Mazighi M, Meseguer E, Labreuche J, Serfaty JM, Laissy JP, Lavallee PC, Cabrejo L, Guidoux C, Lapergue B, Klein IF, et al. Dramatic recovery in acute ischemic stroke is associated with arterial recanalization grade and speed. Stroke. 2012;43(11):2998-3002.

167. Alexandrov AV, Hall CE, Labiche LA, Wojner AW, Grotta JC. Ischemic stunning of the brain: early recanalization without immediate clinical improvement in acute ischemic stroke. Stroke. 2004;35(2):449-52.

168. Baron JC. Perfusion thresholds in human cerebral ischemia: historical perspective and therapeutic implications. Cerebrovasc Dis. 2001;11(Suppl 1): 2-8.

169. Bardutzky J, Shen Q, Henninger N, Schwab S, Duong TQ, Fisher M. Characterizing tissue fate after transient cerebral ischemia of varying duration using quantitative diffusion and perfusion imaging. Stroke. 2007; 38(4):1336-44.

170. Shen Q, Fisher M, Sotak CH, Duong TQ. Effects of reperfusion on ADC and CBF pixel-by-pixel dynamics in stroke: characterizing tissue fates using quantitative diffusion and perfusion imaging. J Cereb Blood Flow Metab. 2004;24(3):280-90.

171. Markus R, Reutens DC, Kazui S, Read S, Wright P, Pearce DC, Tochon-Danguy $\mathrm{HJ}$, Sachinidis JI, Donnan GA. Hypoxic tissue in ischaemic stroke: persistence and clinical consequences of spontaneous survival. Brain. 2004;127(Pt 6): 1427-36.

172. Darby DG, Barber PA, Gerraty RP, Desmond PM, Yang Q, Parsons M, Li T, Tress BM, Davis SM. Pathophysiological topography of acute ischemia by combined diffusion-weighted and perfusion MRI. Stroke. 1999;30(10): 2043-52.

173. Baron JC. Mapping the ischaemic penumbra with PET: implications for acute stroke treatment. Cerebrovasc Dis. 1999;9(4):193-201.

174. Choi JH, Bateman BT, Mangla S, Marshall RS, Prabhakaran S, Chong J, Mohr JP, Mast H, Pile-Spellman J. Endovascular recanalization therapy in acute ischemic stroke. Stroke. 2006:37(2):419-24.

175. Bang OY, Saver JL, Buck BH, Alger JR, Starkman S, Ovbiagele B, Kim D, Jahan $R$, Duckwiler GR, Yoon SR, et al. Impact of collateral flow on tissue fate in acute ischaemic stroke. J Neurol Neurosurg Psychiatry. 2008;79(6):625-9.

176. Leng X, Fang H, Leung TW, Mao C, Miao Z, Liu L, Wong KS, Liebeskind DS. Impact of collaterals on the efficacy and safety of endovascular treatment in acute ischaemic stroke: a systematic review and meta-analysis. J Neurol Neurosurg Psychiatry. 2016;87(5):537-44.

177. Mazighi M, Chaudhry SA, Ribo M, Khatri P, Skoloudik D, Mokin M, Labreuche J, Meseguer E, Yeatts SD, Siddiqui AH, et al. Impact of onset-to-reperfusion time on stroke mortality: a collaborative pooled analysis. Circulation. 2013; 127(19):1980-5.

178. Leker RR, Eichel R, Keigler G, Gomori JM, Cohen JE. Occlusion site does not impact outcome in patients with carotid stroke undergoing endovascular reperfusion. Int J Stroke. 2015;10(4):560-4.

179. Leslie-Mazwi TM, Hirsch JA, Falcone GJ, Schaefer PW, Lev MH, Rabinov JD, Rost NS, Schwamm L, Gonzalez RG. Endovascular stroke treatment outcomes after patient selection based on magnetic resonance imaging and clinical criteria. JAMA neurol. 2016;73(1):43-9.

180. Leigh R, Zaidat OO, Suri MF, Lynch G, Sundararajan S, Sunshine JL, Tarr R, Selman W, Landis DM, Suarez JI. Predictors of hyperacute clinical worsening 
in ischemic stroke patients receiving thrombolytic therapy. Stroke. 2004; 35(8):1903-7.

181. Alvarez-Sabin J, Molina CA, Ribo M, Arenillas JF, Montaner J, Huertas R, Santamarina E, Rubiera M. Impact of admission hyperglycemia on stroke outcome after thrombolysis: risk stratification in relation to time to reperfusion. Stroke. 2004;35(11):2493-8.

182. Arnold M, Mattle S, Galimanis A, Kappeler L, Fischer U, Jung S, De Marchis GM, Gralla J, Mono ML, Brekenfeld C, et al. Impact of admission glucose and diabetes on recanalization and outcome after intra-arterial thrombolysis for ischaemic stroke. Int J Stroke. 2014;9(8):985-91.

183. Koga M, Reutens DC, Wright P, Phan T, Markus R, Pedreira B, Fitt G, Lim I, Donnan GA. The existence and evolution of diffusion-perfusion mismatched tissue in white and gray matter after acute stroke. Stroke. 2005;36(10):2132-7.

184. Kucinski T, Koch C, Eckert B, Becker V, Kromer H, Heesen C, Grzyska U, Freitag HJ, Rother J, Zeumer H. Collateral circulation is an independent radiological predictor of outcome after thrombolysis in acute ischaemic stroke. Neuroradiology. 2003;45(1):11-8.

185. Bhaskar S, Bivard A, Stanwell P, Parsons M, Attia JR, Nilsson M, Levi C. Baseline collateral status and infarct topography in post-ischaemic perilesional hyperperfusion: an arterial spin labelling study. J Cereb Blood Flow Metab. 2017;37(3):1148-62.

186. Lima FO, Furie KL, Silva GS, Lev MH, Camargo EC, Singhal AB, Harris GJ, Halpern EF, Koroshetz WJ, Smith WS, et al. The pattern of leptomeningeal collaterals on CT angiography is a strong predictor of long-term functional outcome in stroke patients with large vessel intracranial occlusion. Stroke. 2010;41(10):2316-22.

187. Liebeskind DS, Tomsick TA, Foster LD, Yeatts SD, Carrozzella J, Demchuk AM, Jovin TG, Khatri P, von Kummer R, Sugg RM, et al. Collaterals at angiography and outcomes in the interventional Management of Stroke (IMS) III trial. Stroke. 2014;45(3):759-64.

188. Sheth SA, Sanossian N, Hao Q, Starkman S, Ali LK, Kim D, Gonzalez NR, Tateshima S, Jahan R, Duckwiler GR, et al. Collateral flow as causative of good outcomes in endovascular stroke therapy. J Neurointerv Surg. 2016; 8(1):2-7.

189. Miteff F, Levi CR, Bateman GA, Spratt N, McElduff P, Parsons MW. The independent predictive utility of computed tomography angiographic collateral status in acute ischaemic stroke. Brain. 2009;132(Pt 8):2231-8.

190. Seyman E, Shaim H, Shenhar-Tsarfaty S, Jonash-Kimchi T, Bornstein NM, Hallevi $\mathrm{H}$. The collateral circulation determines cortical infarct volume in anterior circulation ischemic stroke. BMC Neurol. 2016;16(1):206.

191. Marks MP, Lansberg MG, Mlynash M, Olivot JM, Straka M, Kemp S, McTaggart R, Inoue M, Zaharchuk G, Bammer R, et al. Effect of collateral blood flow on patients undergoing endovascular therapy for acute ischemic stroke. Stroke. 2014;45(4):1035-9.

192. Bang OY, Saver JL, Kim SJ, Kim GM, Chung CS, Ovbiagele B, Lee KH, Liebeskind DS. Collateral flow predicts response to endovascular therapy for acute ischemic stroke. Stroke. 2011;42(3):693-9.

193. Liebeskind DS, Kim D, Starkman S, Changizi K, Ohanian AG, Jahan R, Vinuela F. Collateral failure? Late mechanical thrombectomy after failed intravenous thrombolysis. J Neuroimaging. 2010;20(1):78-82.

194. Tsivgoulis G, Safouris A, Katsanos AH, Arthur AS, Alexandrov AV. Mechanical thrombectomy for emergent large vessel occlusion: a critical appraisal of recent randomized controlled clinical trials. Brain Behav. 2016;6(2):e00418.

195. Mokin M, Fargen KM, Primiani CT, Ren Z, Dumont TM, Brasiliense LBC, Dabus G, Linfante I, Kan P, Srinivasan VM, et al. Vessel perforation during stent retriever thrombectomy for acute ischemic stroke: technical details and clinical outcomes. J Neurointerv Surg. 2017;9(10):922-28.

196. Schumacher HC, Meyers PM, Yavagal DR, Harel NY, Elkind MS, Mohr JP, PileSpellman J. Endovascular mechanical thrombectomy of an occluded superior division branch of the left MCA for acute cardioembolic stroke. Cardiovasc Intervent Radiol. 2003;26(3):305-8.

197. Kwolek CJ, Crawford RS. Training the next generation of vascular specialists: current status and future perspectives. J Endovasc Ther. 2009;16(1_suppl): $42-52$.

198. Endovascular Therapy Following Imaging Evaluation for Ischemic Stroke 3 (DEFUSE 3). [https://clinicaltrials.gov/ct2/show/NCT02586415].

199. POSITIVE Stroke Clinical Trial [https://clinicaltrials.gov/ct2/show/ NCT01852201].

200. Trevo and Medical Management Versus Medical Management Alone in Wake Up and Late Presenting Strokes [https://clinicaltrials.gov/ct2/show/ NCT02142283].
201. Griessenauer CJ, Schirmer CM. Dawn of an even newer era: mechanical Thrombectomy for acute ischemic stroke beyond 6 to 8 hours. World Neurosurg. 2017;104:968-9.

202. Hacke W. A new DAWN for imaging-based selection in the treatment of acute stroke. N Engl J Med. 2018;378(1):81-3.

203. Brinjikji W, Murad MH, Rabinstein AA, Cloft HJ, Lanzino G, Kallmes DF. Conscious sedation versus general anesthesia during endovascular acute ischemic stroke treatment: a systematic review and meta-analysis. AJNR Am J Neuroradiol. 2015;36(3):525-9.

204. Abou-Chebl A, Lin R, Hussain MS, Jovin TG, Levy El, Liebeskind DS, Yoo AJ Hsu DP, Rymer MM, Tayal AH, et al. Conscious sedation versus general anesthesia during endovascular therapy for acute anterior circulation stroke: preliminary results from a retrospective, multicenter study. Stroke. 2010; $41(6): 1175-9$.

205. John S, Thebo U, Gomes J, Saqqur M, Farag E, Xu J, Wisco D, Uchino K, Hussain MS. Intra-arterial therapy for acute ischemic stroke under general anesthesia versus monitored anesthesia care. Cerebrovasc Dis. 2014;38(4):262-7.

206. van den Berg LA, Koelman DL, Berkhemer OA, Rozeman AD, Fransen PS, Beumer D, Dippel DW, van der Lugt A, van Oostenbrugge RJ, van Zwam WH, et al. Type of anesthesia and differences in clinical outcome after intraarterial treatment for ischemic stroke. Stroke. 2015;46(5):1257-62.

207. Sedation vs. Intubation for Endovascular Stroke TreAtment (SIESTA). [https:// clinicaltrials.gov/ct2/show/NCT02126085].

208. General Or Local Anaestesia in Intra Arterial THerapy (GOLIATH) [https:// clinicaltrials.gov/ct2/show/NCT02317237].

209. Sedation Versus General Anesthesia for Endovascular Therapy in Acute Stroke - Impact on Neurological Outcome (ANSTROKE). [https://clinicaltrials. gov/ct2/show/NCT01872884].

210. Mokin M, Rojas H, Levy El. Randomized trials of endovascular therapy for stroke [mdash] impact on stroke care. Nat Rev Neurol. 2016;12(2):86-94.

211. Lowhagen Henden P, Rentzos A, Karlsson JE, Rosengren L, Leiram B, Sundeman H, Dunker D, Schnabel K, Wikholm G, Hellstrom M, et al. General anesthesia versus conscious sedation for endovascular treatment of acute ischemic stroke: the AnStroke trial (anesthesia during stroke). Stroke. 2017; 48(6):1601-7.

212. Schonenberger S, Pfaff J, Uhlmann L, Klose C, Nagel S, Ringleb PA, Hacke W, Kieser M, Bendszus M, Mohlenbruch MA, et al. The impact of conscious sedation versus general anesthesia for stroke Thrombectomy on the predictive value of collateral status: a post hoc analysis of the SIESTA trial. AJNR Am J Neuroradiol. 2017;38(8):1580-85.

213. Schonenberger S, Uhlmann L, Hacke W, Schieber S, Mundiyanapurath S, Purrucker JC, Nagel S, Klose C, Pfaff J, Bendszus M, et al. Effect of conscious sedation vs general anesthesia on early neurological improvement among patients with ischemic stroke undergoing endovascular Thrombectomy: a randomized clinical trial. JAMA. 2016;316(19):1986-96.

214. Schonewille WJ, Algra A, Serena J, Molina CA, Kappelle LJ. Outcome in patients with basilar artery occlusion treated conventionally. J Neurol Neurosurg Psychiatry. 2005;76(9):1238-41.

215. Tountopoulou A, Ahl B, Weissenborn K, Becker H, Goetz F. Intra-arterial thrombolysis using rt-PA in patients with acute stroke due to vessel occlusion of anterior and/or posterior cerebral circulation. Neuroradiology. 2008:50(1):75-83.

216. Lindsberg PJ, Mattle HP. Therapy of basilar artery occlusion: a systematic analysis comparing intra-arterial and intravenous thrombolysis. Stroke. 2006; 37(3):922-8.

217. Schonewille WJ, Wijman CA, Michel P, Rueckert CM, Weimar C, Mattle HP, Engelter ST, Tanne D, Muir KW, Molina CA et al: Treatment and outcomes of acute basilar artery occlusion in the basilar artery international cooperation study (BASICS): a prospective registry study. Lancet Neurol 2009, 8(8):724-730.

218. Nagel S, Kellert L, Mohlenbruch M, Bosel J, Rohde S, Ringleb P. Improved clinical outcome after acute basilar artery occlusion since the introduction of endovascular thrombectomy devices. Cerebrovasc Dis. 2013;36(5-6):394-400.

219. Nagel S, Schellinger PD, Hartmann M, Juettler E, Huttner HB, Ringleb P, Schwab S, Kohrmann M. Therapy of acute basilar artery occlusion: intraarterial thrombolysis alone vs bridging therapy. Stroke. 2009;40(1):140-6.

220. Pfefferkorn T, Mayer TE, Opherk C, Peters N, Straube A, Pfister HW, Holtmannspotter M, Muller-Schunk S, Wiesmann M, Dichgans M. Staged escalation therapy in acute basilar artery occlusion: intravenous thrombolysis and on-demand consecutive endovascular mechanical thrombectomy: preliminary experience in 16 patients. Stroke. 2008;39(5): 1496-500. 
221. Basilar Artery International Cooperation Study (BASICS) [https://clinicaltrials. gov/ct2/show/NCT01717755].

222. van der Hoeven EJ, Schonewille WJ, Vos JA, Algra A, Audebert HJ, Berge E, Ciccone A, Mazighi M, Michel P, Muir KW, et al. The basilar artery international cooperation study (BASICS): study protocol for a randomised controlled trial. Trials. 2013;14:200

223. Huo X, Gao F, Sun X, Ma N, Song L, Mo D, Liu L, Wang B, Zhang X, Miao Z. Endovascular mechanical Thrombectomy with the solitaire device for the treatment of acute basilar artery occlusion. World neurosurg. 2016;89:301-8.

224. Mourand I, Machi P, Milhaud D, Picot MC, Lobotesis K, Arquizan C, Costalat V, Heroum C, Sablot D, Bouly S, et al. Mechanical thrombectomy with the solitaire device in acute basilar artery occlusion. J Neurointerv Surg. 2014; 6(3):200-4.

225. Direct Transfer to an Endovascular Center Compared to Transfer to the Closest Stroke Center in Acute Stroke Patients With Suspected Large Vessel Occlusion. [https://clinicaltrials.gov/ct2/show/NCT02795962].

226. Statistical Plan for the MOST trial [http://www.berryconsultants.com/wpcontent/uploads/2015/08/MOST.pdf].

227. Alberts MJ, Latchaw RE, Jagoda A, Wechsler LR, Crocco T, George MG, Connolly ES, Mancini B, Prudhomme S, Gress D, et al. Revised and updated recommendations for the establishment of primary stroke centers: a summary statement from the brain attack coalition. Stroke. 2011;42(9):2651-65.

228. Latchaw RE, Alberts MJ, Lev MH, Connors JJ, Harbaugh RE, Higashida RT, Hobson R, Kidwell CS, Koroshetz WJ, Mathews V, et al. Recommendations for imaging of acute ischemic stroke: a scientific statement from the American Heart Association. Stroke. 2009;40(11):3646-78.

229. Pereira VM, Krings T. Comeback victory. Am J Neuroradiol. 2015;36(5):821-4.

230. Malhotra K, Liebeskind DS. Imaging in endovascular stroke trials. J Neuroimaging. 2015;25(4):517-27.

231. Marler JR, Tilley BC, Lu M, Brott TG, Lyden PC, Grotta JC, Broderick JP, Levine SR, Frankel MP, Horowitz SH, et al. Early stroke treatment associated with better outcome: the NINDS rt-PA stroke study. Neurology. 2000;55(11):1649-55.

232. Wahlgren N, Ahmed N, Davalos A, Ford GA, Grond M, Hacke W, Hennerici MG, Kaste M, Kuelkens S, Larrue V, et al. Thrombolysis with alteplase for acute ischaemic stroke in the safe implementation of Thrombolysis in stroke-monitoring study (SITS-MOST): an observational study. Lancet. 2007; 369(9558):275-82.

233. Toni D, Lorenzano S, Agnelli G, Guidetti D, Orlandi G, Semplicini A, Toso V, Caso V, Malferrari G, Fanucchi S, et al. Intravenous thrombolysis with rt-PA in acute ischemic stroke patients aged older than 80 years in Italy. Cerebrovasc Dis. 2008;25(1-2):129-35.

234. Rha JH, Shrivastava VP, Wang Y, Lee KE, Ahmed N, Bluhmki E, Hermansson $\mathrm{K}$, Wahlgren N. Thrombolysis for acute ischaemic stroke with alteplase in an Asian population: results of the multicenter, multinational safe implementation of Thrombolysis in stroke-non-European Union world (SITSNEW). Int J Stroke. 2014;9(Suppl A100):93-101.

235. Grunwald IQ, Walter S, Papanagiotou P, Krick C, Hartmann K, Dautermann A, Fassbender K, Haass A, Bolar LJ, Reith W, et al. Revascularization in acute ischaemic stroke using the penumbra system: the first single center experience. Eur J Neurol. 2009;16(11):1210-6.

236. Hui FK, Narayanan S, Cawley CM. Posterior-to-anterior circulation access using the penumbra stroke system for mechanical thrombectomy of a right middle cerebral artery thrombus. World neurosurg. 2010;73(1):17-21.

237. Kalia JS, Zaidat OO. Using a distal access catheter in acute stroke intervention with penumbra, merci and gateway. A technical case report. Interv Neuroradiol. 2009;15(4):421-4.

238. Chow K, Gobin YP, Saver J, Kidwell C, Dong P, Vinuela F. Endovascular treatment of dural sinus thrombosis with rheolytic thrombectomy and intraarterial thrombolysis. Stroke. 2000;31(6):1420-5.

239. Curtin KR, Shaibani A, Resnick SA, Russell EJ, Simuni T. Rheolytic catheter thrombectomy, balloon angioplasty, and direct recombinant tissue plasminogen activator thrombolysis of dural sinus thrombosis with preexisting hemorrhagic infarctions. AJNR Am J Neuroradiol. 2004;25(10):1807-11.

240. Dashti SR, Hu YC, Yao T, Fiorella D, Mitha AP, Albuquerque FC, McDougall CG. Mechanical thrombectomy as first-line treatment for venous sinus thrombosis: technical considerations and preliminary results using the AngioJet device. J Neurointerv Surg. 2013;5(1):49-53.

241. Iskander A, Nayak A, Chauhan MS. Submassive pulmonary embolism and paradoxical embolic stroke treated with percutaneous rheolytic thrombectomy and closure of the patent foramen ovale. Catheter Cardiovasc Interv. 2005;64(3):356-60.
242. Tomsick T, Broderick J, Carrozella J, Khatri P, Hill M, Palesch Y, Khoury J. Revascularization results in the interventional Management of Stroke II trial. AJNR Am J Neuroradiol. 2008;29(3):582-7.

243. Kim SM, Lee DH, Kwon SU, Choi CG, Kim SJ, Suh DC. Treatment of acute ischemic stroke: feasibility of primary or secondary use of a self-expanding stent (Neuroform) during local intra-arterial thrombolysis. Neuroradiology. 2012;54(1):35-41.

244. Mitra D, Herwadkar A, Gholkar A. Use of neuroform stent in a patient with acute stroke caused by spontaneous petrous segment internal carotid artery dissection: a case report. Interv Neuroradiol. 2004;10(2):155-60.

245. Dumont TM, Natarajan SK, Eller JL, Mocco J, Kelly WH Jr, Snyder KV, Hopkins LN, Siddiqui AH, Levy El. Primary stenting for acute ischemic stroke using the Enterprise vascular reconstruction device: early results. J Neurointerv Surg. 2014;6(5):363-72.

246. Lee KY, Chen DY, Hsu HL, Chen CJ, Tseng YC. Undersized angioplasty and stenting of symptomatic intracranial tight stenosis with Enterprise: evaluation of clinical and vascular outcome. Interv Neuroradiol. 2016;22(2):187-95.

247. Natarajan SK, Sonig A, Mocco J, Dumont TM, Thind H, Hartney ML, Snyder KV, Hopkins LN, Siddiqui AH, Levy El. Primary stenting for acute ischemic stroke using the Enterprise intracranial stent: 2-year results of a phase-I trial. J Vasc Interv Neurol. 2015;8(3):62-7.

248. Coutinho JM, Liebeskind DS, Slater LA, Nogueira RG, Baxter BW, Levy El, Siddiqui AH, Goyal M, Zaidat OO, Davalos A, et al. Mechanical Thrombectomy for isolated M2 occlusions: a post hoc analysis of the STAR, SWIFT, and SWIFT PRIME studies. AJNR Am J Neuroradiol. 2016;37(4):667-72.

249. Coutinho JM, Liebeskind DS, Slater LA, Nogueira RG, Clark W, Davalos A, Bonafe A, Jahan R, Fischer U, Gralla J, et al. Combined intravenous Thrombolysis and Thrombectomy vs Thrombectomy alone for acute ischemic stroke: a pooled analysis of the SWIFT and STAR studies. JAMA Neurol. 2017;74(3):268-74.

250. Lopez-Cancio E, Jovin TG, Cobo E, Cerda N, Jimenez M, Gomis M, Hernandez-Perez M, Caceres C, Cardona P, Lara B, et al. Endovascular treatment improves cognition after stroke: a secondary analysis of REVASCAT trial. Neurology. 2017;88(3):245-51.

251. Mokin M, Levy El, Siddiqui AH, Goyal M, Nogueira RG, Yavagal DR. V MP, Saver JL. Association of clot burden score with radiographic and clinical outcomes following solitaire stent retriever thrombectomy: analysis of the SWIFT PRIME trial. J Neurointerv Surg. 2016;9(10):929-32.

252. Shireman TI, Wang K, Saver JL, Goyal M, Bonafe A, Diener HC, Levy El, Pereira VM, Albers GW, Cognard C, et al. Cost-effectiveness of solitaire stent retriever Thrombectomy for acute ischemic stroke: results from the SWIFT-PRIME trial (solitaire with the intention for Thrombectomy as primary endovascular treatment for acute ischemic stroke). Stroke. 2017;48(2):379-87.

253. Broussalis E, Trinka E, Hitzl W, Wallner A, Chroust V, Killer-Oberpfalzer M. Comparison of stent-retriever devices versus the merci retriever for endovascular treatment of acute stroke. AJNR Am J Neuroradiol. 2013;34(2):366-72.

254. Davalos A, Pereira VM, Chapot R, Bonafe A, Andersson T, Gralla J. Retrospective multicenter study of solitaire FR for revascularization in the treatment of acute ischemic stroke. Stroke. 2012;43(10):2699-705.

255. Dippel DW, Majoie CB, Roos YB, van der Lugt A, van Oostenbrugge RJ, van Zwam WH, Lingsma HF, Koudstaal PJ, Treurniet KM, van den Berg LA, et al. Influence of device choice on the effect of intra-arterial treatment for acute ischemic stroke in MR CLEAN (multicenter randomized clinical trial of endovascular treatment for acute ischemic stroke in the Netherlands). Stroke. 2016;47(10):2574-81.

256. Haussen DC, Lima A, Nogueira RG. The Trevo XP $3 \times 20$ mm retriever ('Baby Trevo') for the treatment of distal intracranial occlusions. J Neurointerv Surg. 2016;8(3):295-9.

257. Hentschel KA, Daou B, Chalouhi N, Starke RM, Clark S, Gandhe A, Jabbour P, Rosenwasser $\mathrm{R}$, Tjoumakaris $\mathrm{S}$. Comparison of non-stent retriever and stent retriever mechanical thrombectomy devices for the endovascular treatment of acute ischemic stroke. J Neurosurg. 2016;126(4):1123-30.

258. Imahori T, Tanaka K, Koyama J, Arai A, Shiomi R, Iwahashi H, Yokote A, Matsushima K, Matsui D, Kobayashi M, et al. Mechanical Thrombectomy using the Trevo ProVue in 50 consecutive patients with anterior circulation stroke: a single-center experience after approval of the stent retriever in Japan. Neurol Med Chir (Tokyo). 2017;57(3):128-35.

259. Kim SK, Baek BH, Heo TW, Yoon W. Successful cross-circulation stentretriever Embolectomy through posterior communicating artery for acute MCA occlusion by using Trevo XP ProVue. Neurointervention. 2016;11(1):55-8. 
260. Rohde S, Haehnel S, Herweh C, Pham M, Stampfl S, Ringleb PA, Bendszus M. Mechanical thrombectomy in acute embolic stroke: preliminary results with the revive device. Stroke. 2011;42(10):2954-6.

261. Saleh M, Spence JN, Nayak S, Pearce G, Tennuci C, Roffe C. Safety and efficacy of the Aperio thrombectomy device when compared to the solitaire $A B / F R$ and the revive devices in a pulsatile flow system. Am J Cardiovasc Dis. 2012;2(4):301-8.

262. Kallenberg K, Solymosi L, Taschner CA, Berkefeld J, Schlamann M, Jansen O, Arnold S, Tomandl B, Knauth M, Turowski B: Endovascular stroke therapy with the Aperio thrombectomy device. J Neurointerv Surg 2016, 8(8):834-839.

263. Roth C, Junk D, Papanagiotou P, Keuler A, Korner H, Schumacher M, Reith W. A comparison of 2 stroke devices: the new Aperio clot-removal device and the solitaire AB/FR. AJNR Am J Neuroradiol. 2012;33(7):1317-20.

264. Kabbasch C, Mpotsaris A, Liebig T, Soderman M, Holtmannspotter M, Cronqvist M, Thornton J, Mendes Pereira V, Andersson T. First-in-man procedural experience with the novel EmboTrap(R) revascularization device for the treatment of ischemic stroke-a European multicenter series. Clin Neuroradiol. 2016:26(2):221-8.

265. Prothmann S, Schwaiger BJ, Gersing AS, Reith W, Niederstadt T, Felber A, Kurre W. Acute Recanalization of Thrombo-embolic ischemic stroke with pREset (ARTESp): the impact of occlusion time on clinical outcome of directly admitted and transferred patients. J Neurointerv Surg. 2017;9(9): 817-22.

266. Cerejo R, John S, Bauer A, Hussain MS, Bain M, Rasmussen P, Hui F, Masaryk $T$, Toth $G$. Emergent mechanical thrombectomy for acute stroke using the Mindframe capture LP system: initial single-center experience. J Neurointerv Surg. 2016;8(11):1178-80.

267. Protto S, Pienimaki JP, Seppanen J, Matkaselka I, Ollikainen J, Numminen H, Sillanpaa N. TREVO and capture LP have equal technical success rates in mechanical thrombectomy of proximal and distal anterior circulation occlusions. J Neurointerv Surg. 2017;9(7):644-9.

268. Raoult H, Redjem H, Bourcier R, Gaultier-Lintia A, Daumas-Duport B, Ferre JC, Eugene F, Fahed R, Bartolini B, Piotin M, et al. Mechanical thrombectomy with the ERIC retrieval device: initial experience. J Neurointerv Surg. 2017; 9(6):574-77

269. Mohlenbruch MA, Kabbasch C, Kowoll A, Broussalis E, Sonnberger M, Muller M, Wiesmann M, Trenkler J, Killer-Oberpfalzer M, Weber W, et al. Multicenter experience with the new SOFIA plus catheter as a primary local aspiration catheter for acute stroke thrombectomy. J Neurointerv Surg. 2017;9(12): 1223-27.

270. Stampfl S, Kabbasch C, Muller M, Mpotsaris A, Brockmann M, Liebig T, Wiesmann M, Bendszus M, Mohlenbruch MA. Initial experience with a new distal intermediate and aspiration catheter in the treatment of acute ischemic stroke: clinical safety and efficacy. J Neurointerv Surg. 2016;8(7):714-8.

271. Wong JH, Do HM, Telischak NA, Moraff AM, Dodd RL, Marks MP, Ingle SM, Heit J. Initial experience with SOFIA as an intermediate catheter in mechanical thrombectomy for acute ischemic stroke. J Neurointerv Surg. 2016;

272. Kowoll A, Weber A, Mpotsaris A, Behme D, Weber W. Direct aspiration first pass technique for the treatment of acute ischemic stroke: initial experience at a European stroke center. J Neurointerv Surg. 2016;8(3):230-4.

273. Kim YS, Kwak HS, Chung GH, Hwang SB. Manual aspiration thrombectomy using the penumbra catheter in patients with acute M1 occlusion: a singlecenter study. Interv Neuroradiol. 2015;21(6):694-9.

274. Park JS, Kwak HS. Manual aspiration Thrombectomy using penumbra catheter in patients with acute M2 occlusion : a single-center analysis. J Korean Neurosurg Soc. 2016;59(4):352-6.

275. Schumacher HC, Gupta R, Higashida RT, Meyers PM. Advances in revascularization for acute ischemic stroke treatment. Expert Rev Neurother. 2005;5(2):189-201.

276. Mahon BR, Nesbit GM, Barnwell SL, Clark W, Marotta TR, Weill A, Teal PA, Qureshi Al. North American clinical experience with the EKOS MicroLysUS infusion catheter for the treatment of embolic stroke. AJNR Am J Neuroradiol. 2003;24(3):534-8.

277. Jiang WJ, Yu W, Du B, Gao F, Cui LY. Outcome of patients with $>/=70 \%$ symptomatic intracranial stenosis after wingspan stenting. Stroke. 2011; 42(7):1971-5.

278. Li TX, Gao BL, Cai DY, Wang ZL, Zhu LF, Xue JY, Bai WX, He YK, Li L. Wingspan stenting for severe symptomatic intracranial atherosclerotic Stenosis in 433 patients treated at a single medical center. PLoS One. 2015; 10(9):e0139377.
279. Murias Quintana E, Vega Valdes P, Morales Deza E, Gil Garcia A, Cuellar Saenz H, Salgado Bernal AL, Cadenas Rodriguez M, Benavente Fernandez L, Delgado MG, Riesco Perez N, et al. Endovascular reconstruction of internal carotid artery dissection in patients with acute ischemic stroke using the wingspan stent. Interv Neuroradiol. 2016;22(6):700-4.

280. Qureshi Al, Al-Senani FM, Husain S, Janjua NA, Lanzino G, Lavados PM, Nguyen T, Raymond J, Shah QA, Suarez JI, et al. Intracranial angioplasty and stent placement after stenting and aggressive medical management for preventing recurrent stroke in intracranial stenosis (SAMMPRIS) trial: present state and future considerations. J Neuroimaging. 2012;22(1):1-13.

281. Sung SM, Lee TH, Cho HJ, Sol YL, Park KH, Jung DS, Kim CW. Recanalization with wingspan stent for acute middle cerebral artery occlusion in failure or contraindication to intravenous thrombolysis: a feasibility study. AJNR Am J Neuroradiol. 2012;33(6):1156-61.

282. Wang ZL, Gao BL, Li TX, Cai DY, Zhu LF, Xue JY, Bai WX, Li ZS. Outcomes of middle cerebral artery angioplasty and stenting with wingspan at a highvolume center. Neuroradiology. 2016;58(2):161-9.

283. Xavier AR, Tiwari A, Purai N, Rayes M, Pandey P, Kansara A, Narayanan S, Chaturvedi S. Safety and efficacy of intracranial stenting for acute ischemic stroke beyond 8 h of symptom onset. J Neurointerv Surg. 2012;4(2):94-100.

284. Zhao T, Zhu WY, Xiong XY, Li J, Wang L, Ding HY, Wei F, Zhou Y, Gong ZL, Cheng $S Y$, et al. Safety and efficacy of wingspan stenting for severe symptomatic atherosclerotic Stenosis of the middle cerebral artery: analysis of 278 continuous cases. J Stroke Cerebrovasc Dis. 2016;25(10):2368-72.

285. Lee MS, Singh V, Wilentz JR, Makkar RR. AngioJet thrombectomy. J Invasive Cardiol. 2004;16(10):587-91.

286. Lee JS, Demchuk AM. Choosing a Hyperacute stroke imaging protocol for proper patient selection and time efficient endovascular treatment: lessons from recent trials. J Stroke. 2015;17(3):221-8.

287. International Multicenter Registry for Mechanical Recanalization Procedures in Acute Stroke [https:/clinicaltrials.gov/ct2/show/NCT01399762].

288. Imaging Guided Patient Selection for Interventional Revascularization Therapy (START) [https:/clinicaltrials.gov/ct2/show/NCT00963989].

289. Endovascular Acute Stroke Intervention Trial - the EASI Trial [https:// clinicaltrials.gov/ct2/show/NCT02157532].

\section{Submit your next manuscript to BioMed Central and we will help you at every step:}

- We accept pre-submission inquiries

- Our selector tool helps you to find the most relevant journal

- We provide round the clock customer support

- Convenient online submission

- Thorough peer review

- Inclusion in PubMed and all major indexing services

- Maximum visibility for your research

Submit your manuscript at www.biomedcentral.com/submit
C Biomed Central 